Electrical and Magneto-Electrical Resistivity of Very Dilute CuCr Alloys

Thomas Allyn Vyrostek

A M. S. Thesis Submitted to Iowa State University

\author{
Ames Laboratory, USAEC \\ Iowa State University \\ Ames, Iowa 50010
}

Date Transmitted: July 1974

PREPARED FOR THE U. S. ATOMIC ENERGY COMMISSION DIVISION OF RESEAR CH UNDER CONTRACT NO. W-7405-eng-82

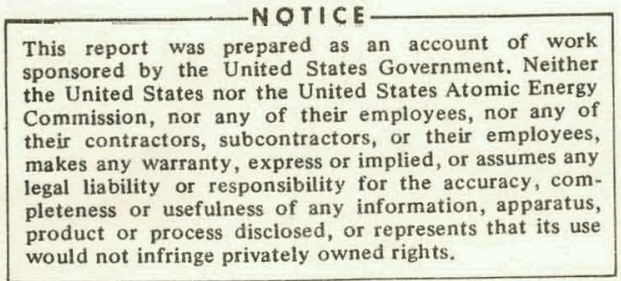




\section{DISCLAIMER}

This report was prepared as an account of work sponsored by an agency of the United States Government. Neither the United States Government nor any agency Thereof, nor any of their employees, makes any warranty, express or implied, or assumes any legal liability or responsibility for the accuracy, completeness, or usefulness of any information, apparatus, product, or process disclosed, or represents that its use would not infringe privately owned rights. Reference herein to any specific commercial product, process, or service by trade name, trademark, manufacturer, or otherwise does not necessarily constitute or imply its endorsement, recommendation, or favoring by the United States Government or any agency thereof. The views and opinions of authors expressed herein do not necessarily state or reflect those of the United States Government or any agency thereof. 


\section{DISCLAIMER}

Portions of this document may be illegible in electronic image products. Images are produced from the best available original document. 
NOTICE

This report was prepared as an account of work sponsored by the United States Government. Neither the United States nor the United States Atomic Energy Commission, nor any of their employees, nor any of their contractors, subcontractors, or their employees, makes any warranty, express or implied, or assumes any legal liability or responsibility for the accuracy, completeness or usefulness of any information, apparatus, product or process disclosed, or represents that its use would not infringe privately owned rights.

Available from: National Technical Information Service Department A

Springfield, VA 22151

Price: Microfiche $\$ 1.45$

Printed Copy $\$ 5.45$ 


\title{
Electrical and magneto-electrical resistivity. of very dilute CuCr alloys
}

by

Thomas Allyn Vyrostek

\author{
A Thesis Submitted to the \\ Graduate Faculty in Partial Fulfillment of \\ The Requirements for the Degree of \\ MASTER OF SCIENCE \\ Department: Physics \\ Major: Solid State Physics
}

Approved:

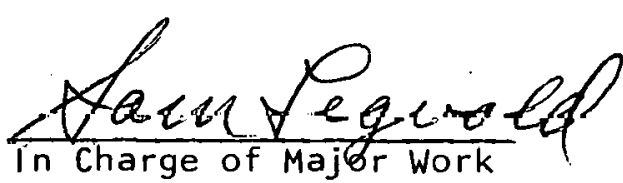

COB Barnef

For the Major Department

For the Graduate College

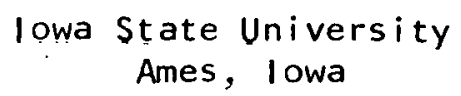


TABLE OF CONTENTS

\begin{tabular}{|c|c|c|c|}
\hline$\therefore$ & & ABSTRACT & $\vec{v}$ \\
\hline CHAPTER & I. & INTRODUCTION & I \\
\hline \multirow{6}{*}{\multicolumn{2}{|c|}{ CHAPTER II. }} & ELECTRICAL RESISTIVITY OF DILUTE CUCr & 3 \\
\hline & & Introduction & 3 \\
\hline & & Sketch of the Basic Theory & 4 \\
\hline & & Experimental Procedure & 9 \\
\hline & & $\begin{array}{l}\text { Presentation and Discussion of Experimental } \\
\text { Results }\end{array}$ & 26 \\
\hline & & Conclusion & 46 \\
\hline \multirow[t]{6}{*}{ CHAPTER } & 111. & $\begin{array}{l}\text { MAGNETO-ELECTR I CAL RESISTIVITY OF DILUTE } \\
\text { CUCr ALLOYS }\end{array}$ & 47 \\
\hline & & Introduction & 47 \\
\hline & & Sketch of the Basic Theory & 48 \\
\hline & & Experimental Procedure & 51 \\
\hline & & $\begin{array}{l}\text { Presentation and Discussion of Experimental } \\
\text { Results }\end{array}$ & 75 \\
\hline & & Conclusion & 93 \\
\hline \multicolumn{3}{|c|}{ REFERENCES } & 97 \\
\hline \multicolumn{3}{|c|}{ ACKNOWLEDGMENTS } & 100 \\
\hline APPENDIX & A. & $\begin{array}{c}\text { LIST OF EQUIPMENT USED IN DETERMINATION } \\
\text { OF RESISTIVITY OF CUCr ALLOYS }\end{array}$ & 102 \\
\hline APPENDIX & $\mathrm{X} B$. & TABULATION OF CUCr RESISTIVITY DATA & 103 \\
\hline APPENDIX & c. & $\begin{array}{l}\text { LIST OF EQUIPMENT USED IN DETERMINATION } \\
\text { OF MAGNETORESISTIVITY OF CUCR ALLOYS }\end{array}$ & 108 \\
\hline
\end{tabular}




\section{Electrical and magneto-electrical resistivity of very dilute CuCr alloys}

Thomas Allyn Vyrostek
Under the supervision of Sam Legvold
From the Department of Physics
lowa State University*

The electrical resistivity from 1.5 to $80 \mathrm{~K}$ and the longitudinal magnetoresistance from 0 to $95 \mathrm{KOe}$ at $1.9,4.2$ and $25 \mathrm{~K}$ were measured on $\mathrm{Cr}$ in $\mathrm{Cu}$ alloys. The $\mathrm{Cr}$ concentrations were 10, 19.6, 39.1 and $87.4 \mathrm{ppm}$. A pure Cu sample was included. A resistivity minima was observed for each alloy, with $T_{\min }=16.0,17.8,19.4$ and $22.2 \mathrm{~K}$ for the $10,19.6,39.1$ and $87.4 \mathrm{ppm}$ samples, respectively. The temperature of the resistivity minimum is shown to be proportional to the $\mathrm{Cr}$ concentration to the 0.15 power and proportional to the resistivity at the minimum to the 0.19 power. The residual resistivity per ppm $\mathrm{Cr}$ at $25 \mathrm{~K}$ was found to increase $\mathrm{linearly}$ and then level off below $60 \mathrm{ppm}$ indicative of a break down in the $\mathrm{Cr}-\mathrm{Cr}$ interactions. The impurity contribution was found to vary linearly with Log. T for each alloy from 2. to $20 \mathrm{~K}$ indicating complete agreement with Kondo theory. The slopes

\footnotetext{
$\because$ USAEC Report IS-T-634. This work was performed under Contract W-7405-eng-82 with the Atomic Energy Commission.
} 
of the above curves showed linear behavior with concentration. From these slopes, the value of the exchange integral or constant was determined to be approximately $\mathrm{J}=-0.6 \mathrm{eV}$. This value agrees very well with $\mathrm{J}=-0.53 \mathrm{eV}$ found for $\mathrm{Cu} \mathrm{Mn}$ by Croft and indicates again a well behaved Kondo system.

The spin contribution to the magnetoresistivity at $4.2 \mathrm{~K}$ was determined to be negative for the Cucr alloys. This was accomplished by subtracting the $25 \mathrm{~K}$ positive alloy matrix magnetoresistivity contribution from the $4.2 \mathrm{~K}$ value for the total magnetoresistivity. The $10 \mathrm{ppm} \mathrm{Cr}$ sample was also observed at $1.9 \mathrm{~K}$ in magnetic fields from $0-85 \mathrm{k0e}$. No spin saturation was seen in any of the alloys. To substantiate this further, the magnetoresistivity at $63 \mathrm{KOe}$ as a function of temperature was measured and compared to the zero field result, with no substantial difference observed. 
CHAPTER 1. INTRODUCTION

The study of the properties of solids has occupied a major portion of time for the scientific community for many years. Two types of solids of great interest are noble and transition metals. It has been found that when one puts a small amount of transition metal into a noble metal host, one finds markedly different low temperature behavior from either of the pure metals.

One property of these alloys which can be studied is the resistivity as a function of temperature. If one puts a known current, I, through a sample of known length, $\ell$ and area, $A$, then by measuring the voltage difference across the sample, $V$, the resistivity can be calculated from the formula

$$
\rho=\frac{V}{I} \cdot \frac{A}{l}
$$

It has been found in different temperature intervals, that a minimum exists in the resistivity for various combinations of transition metal impurities in non-magnetic metallic hosts. This phenomena is now termed the Kondo Effect after the first man to describe the behavior theoretically.

It is the purpose of this thesis to describe the measurements and results on the study of one set of alloys, Cucr. The alloys are classified as very dilute since the chromium concentrations involved are less than 100 parts per million (ppm). The resistivity 
characteristics were studied in both zero and very high (100 k0e) applied magnetic fields. The method and results of each type of study is presented in Chapters 11 and 111 , respectively. 


\section{CHAPTER II. ELECTRICAL RESISTIVITY OF DILUTE CUCr}

\section{Int roduction}

For many years there have been observed many anomalous properties in dilute solutions of magnetic atoms in non-magnetic metallic hosts. In the late 1920's and early 1930's this was subsequently found to be the case after a rather lengthy study was made on several "pure" metals. The study was performed by Meissner and Voigt (1) on Mg, Mo, Te, Co and Pd. It was only after studying the anomalous properties of Pd with. varying amounts of impurities present that they came to the conclusion that it was indeed an impurity effect that they were observing. Many similar studies were performed in the $30^{\prime}$ s and then again after World War 11 (2). A more recent set of review papers on the experimental aspects is given by Daybell and Steyert, Heeger, and van den Berg (3). Many semiclassical explanations were presented for this behavior but none could account for the wide extent to which the anomalies presented themselves. The more important anomalies are the minimum in the electrical resistivity as a function of temperature, a peak in the specific heat, an extremely large peak in the thermoelectric power, and deviations from a Curie Law for the susceptibility.

The first successful treatment of the anomalous behavior was done in 1964 by Kondo (4). He assumed that the impurities formed localized moments and then these localized moments interacted with the conduction electrons via the s-d Hamiltonian. When he calculated the resistivity he found that the exchange scattering of the conduction electrons at 
the Fermi surface by a localized magnetic moment showed a logarithmic temperature dependence. This is now known as the Kondo Effect.

It is the purpose of this chapter to present a short theoretical sketch and the experimental findings on the Kondo effect in very dilute solutions of chromium in a copper host. The system $\mathrm{CuCr}$ was chosen due to the fact that it has a Kondo temperature (to be defined later) of $2 \mathrm{~K}(5)$. The Kondo temperature is markedly different in different alloys, simple examples being CuMn and CuFe. In CuMn, $T_{K}$ is approximately $0.01 \mathrm{~K}$ which makes work below $T_{K}$ impossible with a simple $\mathrm{He}^{4}$ cryostat. For Cufe, one finds $T_{K}$ to be on the order of $30 K$ which makes data analysis above $T_{K}$ difficult due to the phonon contributions at this relatively high temperature. $\mathrm{CuCr}$ then represented an ideal alloy system for study.

The alloys made had chromium concentrations of 10, 19.6, 39.1, and $87.4 \mathrm{ppm}$. To make this study more interesting, a higher concentration study will be included throughout this chapter by making reference to an alloy of CuCr containing 114 ppm $\mathrm{Cr}$ studied by Eagen and Legvold (6) in a study on the Kondo effect in dilute solutions of c.r in a CuNi host. The resistivity of these alloys as a function of temperature was determined from $1.5-80 \mathrm{~K}$ using the standard four-probe direct current method.

\section{Sketch of the Basic Theory}

In the paper by Kondo (4), came the first real understanding of magnetic impurities in a non-magnetic host. He showed that once the phonon scattering of electrons has died out sufficiently at low temperatures, the low temperature electrical resistivity of a metal containing 
non-interacting paramagnetic impurities might increase with decreasing temperature. This effect is caused by an s-d exchange interaction in addition to simple potential scattering. In this case a strongly energy-dependent electron scattering cross-section may be expected. To approach this problem a first Born approximation calculation was tried initially but it was found that in this case isolated magnetic atoms would not cause a resistance minimum.

Kondo extended the calculation to second order Born approximation. In describing the Hamiltonian, Kondo included a free-electron term and a perturbation term which gave (4)

$$
\begin{aligned}
H_{s d}= & -\left(\frac{J}{N}\right) \sum_{K, K^{\prime}}\left[\left(a_{K}{ }^{*} a_{K}{ }^{\prime}-a_{K_{-}}{ }^{*} a_{K}{ }^{\prime}\right) s_{Z}\right. \\
& \left.+a_{K_{+}}{ }^{*} a_{K}{ }^{\prime} s_{-}+a_{K}{ }^{*} a_{-}{ }^{\prime} s_{+}\right] .
\end{aligned}
$$

This expression is basically the second-quantized form of $H=-J \vec{S} \cdot \vec{S}^{\prime}$. The symbols in the above equation have the usual meaning with $a_{K_{+}}{ }^{*}$ being a creation operator for an electron in a state with wave vector $k$ and spin up, $a_{K}{ }^{\prime}$ being a destruction operator for an electron in a state with wave vector $K^{\prime}$ and spin down, $J$ the exchange integral or constant, $s_{ \pm}=s_{x} \pm i s_{y}$, and $N$ the total number of atoms. It is assumed that the exchange integral is independent of $K$ and $K^{\prime}$, the initial and final wave vectors. For resistivity, the inclusion of potential scattering is unimportant. 
As in any transport calculation, the important quantity to be calculated is the electronic relaxation-time $\tau_{K}$ which Kondo found (in the symbols of Star (7)) to be

$$
\left.\tau_{K}^{-1}=\left[3 \pi^{2} z\right]^{2} S(S+1) C / E_{F} h\right]\left[1+4 J g\left(E_{K}\right)\right]
$$

Here $E_{F}$ is the Fermi energy, $E_{K}$ the energy of the electron with wave vector $K$, $C$ the impurity concentration, and $Z$ the number of conduction electrons for the host. Here $g\left(E_{K}\right)$ gives the strong energy dependence in $\tau_{K}$ needed to get a temperature-dependent resistivity. Functionally,

$$
g\left(E_{K}\right)=\int_{\text {bandwidth }} \frac{\rho(E) f(E)}{E-E_{K}} d E
$$

Using Kondo!s interpretation for evaluating the above integral, one finds for the resistivity (7)

$$
\left.o_{\text {res }}=C \rho_{m}\left[1+\left(3 Z J / E_{F}\right)\right] n T\right]
$$

$$
\text { where } \quad \rho_{m}=3 \pi^{2} m J^{2} S(S+1) V / N e^{2} h E_{F}
$$

For our purposes we will make this last expression more significant by substituting some appropriate numbers for our host metal Cu. First let,

$$
E_{F}=\frac{\hbar^{2} K_{F}{ }^{2}}{2 m}
$$

which gives upon substitution,

$$
\rho_{m}=\frac{3 V h K_{F}{ }^{2}}{8 N e^{2}} \frac{J^{2} s(s+1)}{E_{F}{ }^{2}} .
$$


In the case of $\mathrm{Cu}(8)$,

$$
\begin{aligned}
& \left.\frac{N}{V}\right)_{C u}=8.45 \times 10^{22} \mathrm{~cm}^{-3} \\
& K_{F}=1.36 \times 10^{8} \mathrm{~cm}^{-1} \\
& e=4.803 \times 10^{-10} \mathrm{esu} \\
& h=6.626 \times 10^{-27} \mathrm{erg} \mathrm{sec} \\
& \rho_{m_{\mathrm{cu}}}=\frac{23.6 \mathrm{~J}^{2} \mathrm{~S}(\mathrm{~S}+1)}{\mathrm{E}_{\mathrm{F}}^{2}} \mu \mathrm{cm} / \mathrm{at} . \% .
\end{aligned}
$$

Therefore, for small amounts of impurities in copper we get for the impurity contribution to the resistivity,

$$
\rho_{\text {Res }} \approx C\left[23\left(\frac{J}{E_{F}}\right)^{2} S(S+1)\right]\left[1+\left(\frac{3 Z J}{E_{F}}\right) \ln T\right] \text { in } \mu \Omega \mathrm{cm} .
$$

This form for $\rho_{\text {Res }}$ will be found later to be advantageous since if one determines $d \rho / d$ In $T$ experimentally and then assumes $E_{F}=7 \mathrm{eV}$ as for copper, one can get a fairly good handle on the value of $J$, the exchange constant or integral.

As can be seen above, the impurity contribution to the resistivity as described by Kondo does vary as In T. Since scattering processes, where the spin projection value does not change, only contribute to the residual resistivity, the In T term must then be a consequence of the spln-flip scattering itself (4). Therefore, for this phenomenon to be due to spin-flip scattering the impurity contribution to resistivity must vary according to in $T$. 
The total resistivity can be given by

$$
\rho=C_{\rho_{i m p}}+C_{\rho_{m}}\left[1+\left(3 J Z / E_{F}\right) \ln T\right]+A T^{5}
$$

Oimp contains all the temperature-independent impurity resistivity not in $\rho_{m}$. The $T^{5}$ term contains the phonon contribution to the resistivity that is due to the copper host lattice. In copper the $T^{5}$ relation holds true up to $20 \mathrm{~K}(8)$. We can therefore seek an expression for $T_{\min }$ as a function of concentration. Setting do/dT $=0$ at $T_{\min }$ in Equation 5 we get

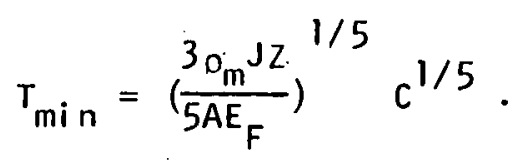

Pearson (9) found in an investigation of many systems, $T_{\min } \propto c^{1 / 5.2}$. Knook (10) found for CuFe that $T_{\min } \alpha c^{1 / 5.3}$. One would expect, then, that we should find this type of relation to hold true for cucr.

It will be noted that Kondo's basic Equation (3) for the impurity contrlbution diverges as $T$ goes to 0 . The basic problem is not important to this study but a few words as to the remedy may be in order at this juncture. The problem of divergence stems from the fact that Kondo was not totally justified in going only to second order in his Born approximation series. Thus the entire series, or a non-perturbation method must be used. After an initial attempt at removing the divergence by Abrikosov $(11,12)$, Suhl (13) tried another method of exact solution but found that the resistivity due to an exchange interaction went to zero at $T=0$. The problem has been corrected by Suhl and Wong (14) 
and by a Green's functional approach by Nagaoka (15.). I refer an interested reader in this aspect of the theory to the cited references.

The final point of interest to us is the Kondo temperature $T_{K}$ alluded to in the introduction. Basically, $T_{K}$ is the temperature at which the Kondo expression deviates from the observed behavior. It is essentially where the perturbation energy equals the thermal energy and thus signals the breakdown of the perturbation technique, An expression for the Kondo temperature and a more complete explanation can be found in works such as that by Fischer (16).

\section{Experimental Procedure}

\section{Sample preparation}

To start with, one should mention for completeness the type of sample preparation which does not seem to work for CuCr. We prepared $30 \mathrm{mil}$ wire samples by drawing arc-melted, swaged $\mathrm{CuCr}$ fingers through tungsten carbide dies. The wires were subsequently annealed in a vacuum and quenched in ice water. The resistivity results obtained with these samples were unreliable and totally inconsistent. Chemical analysis seemed to indicate that varyilly anuunts of $\mathrm{cr}$ had disappeared in the sample preparation. We concluded that the wire size was probably the main factor, so we switched to a procedure which has been found to be reliable in work on CuNi plus Fe samples (17).

Small pieces of $5 \mathrm{NCU}$ and $5 \mathrm{NCr}$ obtained from the American Smelting and Refining Co。 were first electron beam melted to eliminate volatile contaminants and then a CuCr master was made. After this, weighed 
amounts of copper and the CuCr master were arc melted together some six or seven times over a water cooled copper hearth. The samples were inverted between arc melting operations to maximize the mixing. The samples forthcoming were in the form of short bars (fingers). The latter were cold rolled to a thickness of about $8 \mathrm{~mm}$, annealed in a high vacuum at $800^{\circ} \mathrm{C}$ for one day and then quenched in ice water. To avoid surface contamination and other possible variations in $\mathrm{Cr}$ concentration as discussed earlier, samples $2 \times 2 \times 36 \mathrm{~mm}$ were spark cut from the center of the fingers and hand-polished over emery cloth to $1 \times 1 \times 36 \mathrm{~mm}$.

The $\mathrm{Cr}$ content of the samples was determined by chemical spectrophotometric methods. This method was extremely reliable for samples with $\mathrm{Cr}$ content of $20 \mathrm{ppm}$ or more. In this manner $\mathrm{Cr}$ contents were found to be $19.6,39.1$, and $87.4 \mathrm{ppm}$. For the $10 \mathrm{ppm}$ sample, original sample preparation seems to be the most reliable; this sample was made by arc melting weighed portions of pure $\mathrm{Cu}$ and a portion of the $39.1 \mathrm{ppm}$ $\mathrm{Cr}$ finger as described above. The spark cutting and polishing operations for this sample were the same as for the others.

A pure cu sample was carried through the whole procedure. It had a residual resistivity $(4.2 \mathrm{~K})$ of $7.2 \mathrm{n} \Omega \mathrm{cm}$ and the spectrophotometric analysis showed impurities of $\mathrm{Ni} \sim 8 \mathrm{ppm}, \mathrm{Cr} \sim 1 \mathrm{ppm}$; Fe $\sim 2 \mathrm{ppm}$. Since, as it will be seen later, the resistivity at low temperatures $(1-20 \mathrm{~K})$ was normal and showed no hint of a minimum we cuncluded that about 6 ppm $\mathrm{Ni}$ was indeed the major impurity inasmuch as $\mathrm{Ni}$ impurities produce a residual resistivity of $1.1 \mathrm{n} \Omega \mathrm{cm}$ per ppm in $\mathrm{Cu}(18)$. 
Experimental apparatus

The purpose of this experiment, as mentioned earlier, was to measure the resistivity of dilute CuCr samples from 1.5 to $80 \mathrm{~K}$. The measurements were made by the standard dc four-probe technique. Figures 1-3 show, respectively: the electronic circuit, the sample holder, and the voltage probes used to measure the resisitivity. Figures 4 and 5 show the decade resistance settings for the two temperature-controlling bridge circuits used for temperature regulation during the measurements.

The electronic circuit basically consists of two parts; one to measure the voltage difference between two known points on the sample, and the other, to measure the temperature of the sample. A list of equipment, its use, and Ames Laboratory equipment numbers used in the electronic circuit are given in Appendix A. A measurement of the current through the sample was not necessary for each data point since a current supply was constructed which was stable to better than one part in $10^{6}$. The current used was measured against a National Bureau of Standards resistor to be $149.960 \mathrm{~m} \mathrm{~A}$ with a temperature coefficient of 2 parts in $10^{\prime}$ per degree $F$.

The sample emf was measured by a Guildline 0.10 microvolt potentiometer. The out of balance signal was amplified by a Guildline nanovolt amplifier and fed into a Guildiile secondary galvanometer. A single twelve-position four-pole Leeds and Nurthrup rotary switch was used to reverse both the sample emf polarity and the direction of 
THIS PAGE

\section{WAS INTENTIONALLY LEFT BLANK}


Figure 1. Electronic circuit used to measure the resistivity of CuCr Alloys. 


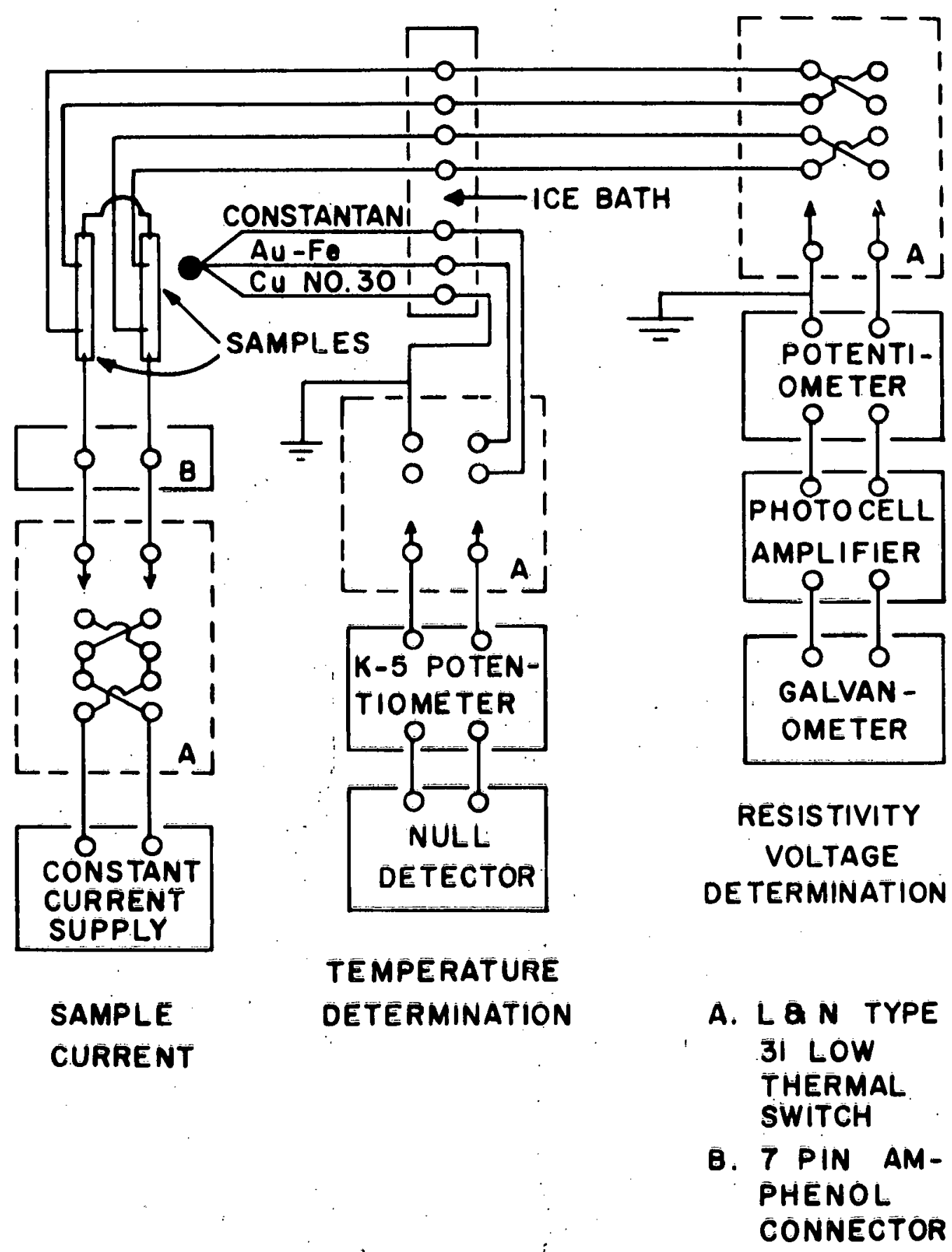


THIS PAGE

\section{WAS INTENTIONALLY LEFT BLANK}


Figure 2. Sample holder used in CuCr resistivity measurement. 


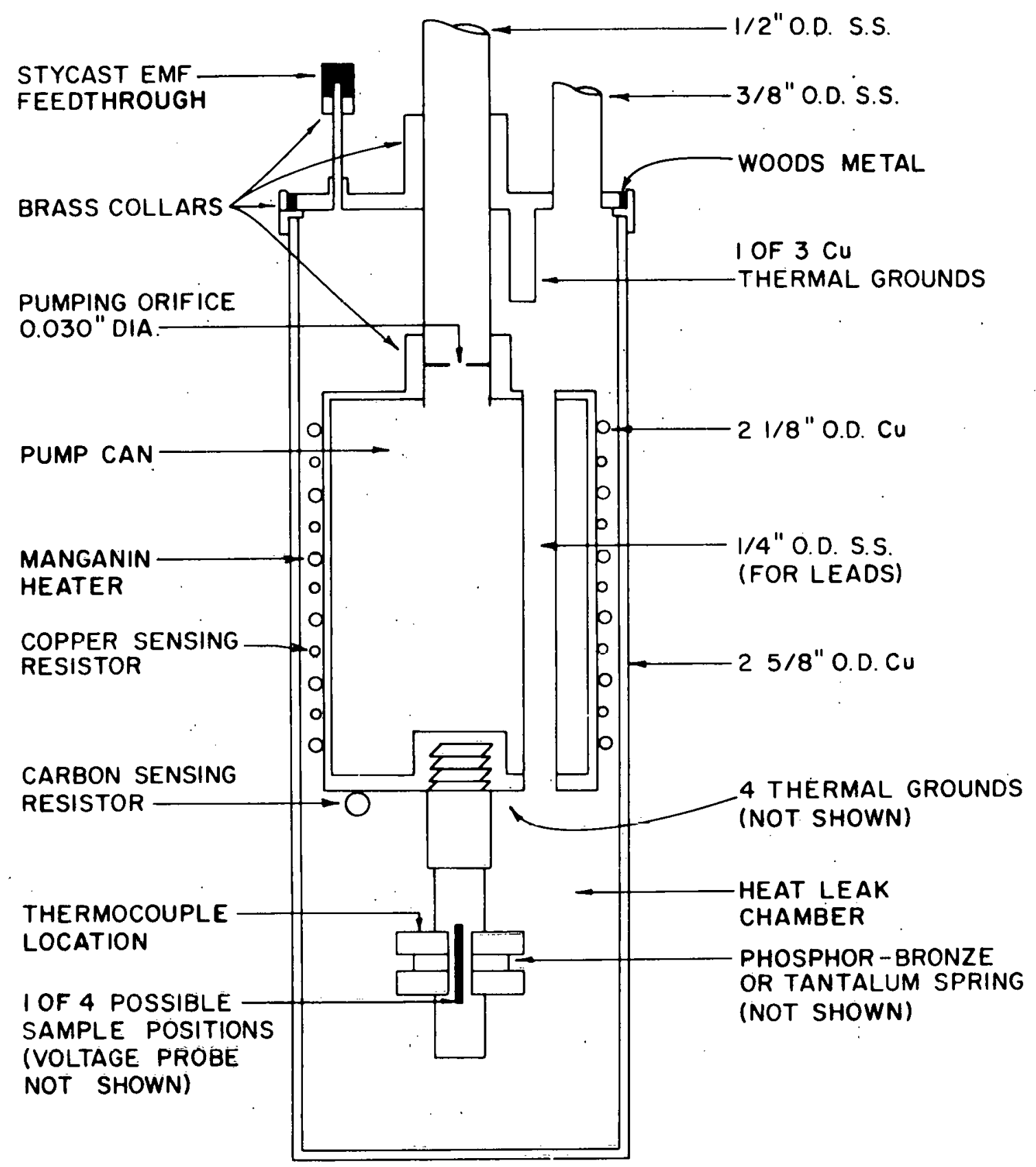


THIS PAGE

\section{WAS INTENTIONALLY LEFT BLANK}


rigure 3. Sample area of the resistivity sample holder. 


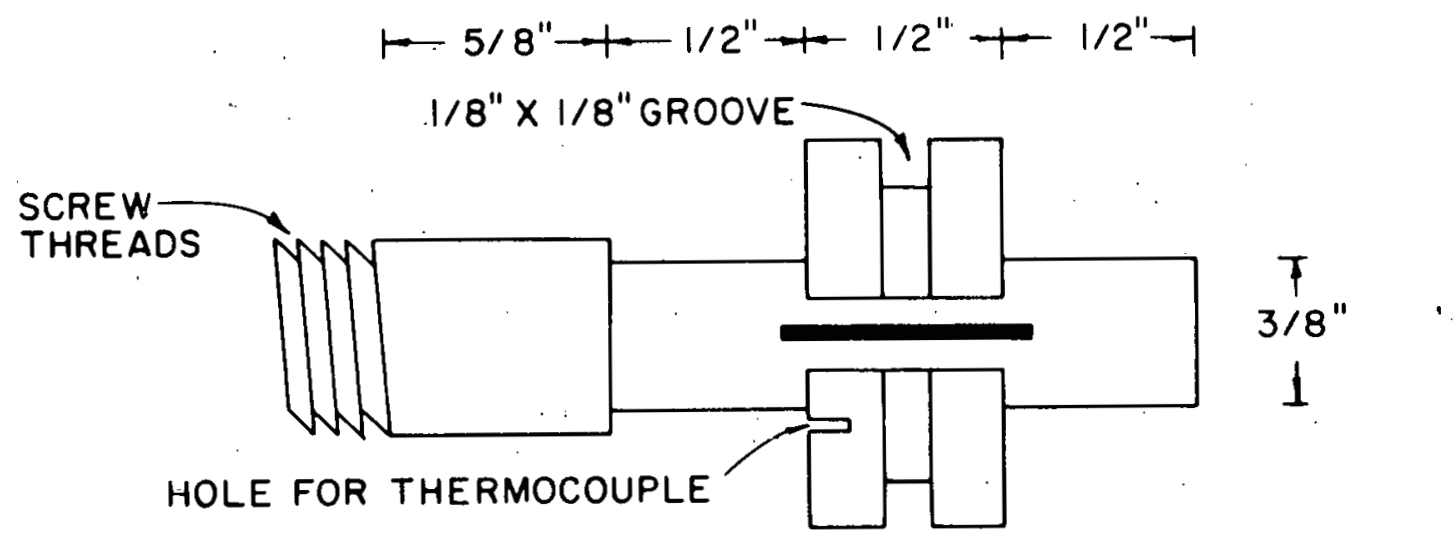

SIDE VIEW

END VIEW
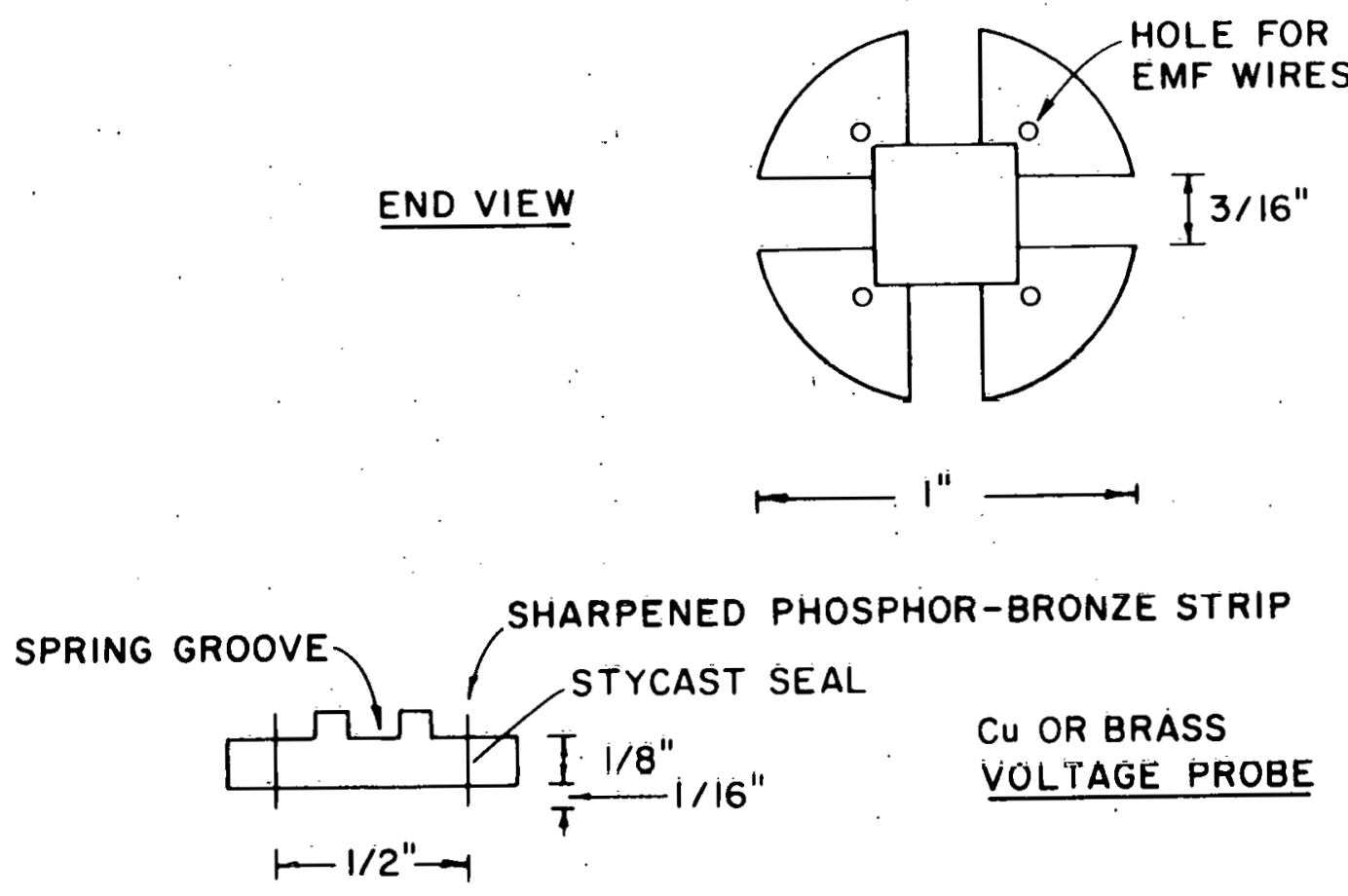
THIS PAGE

\section{WAS INTENTIONALLY LEFT BLANK}


Figure 4. Decade resistance settings used with carbon temperature sensnr. 


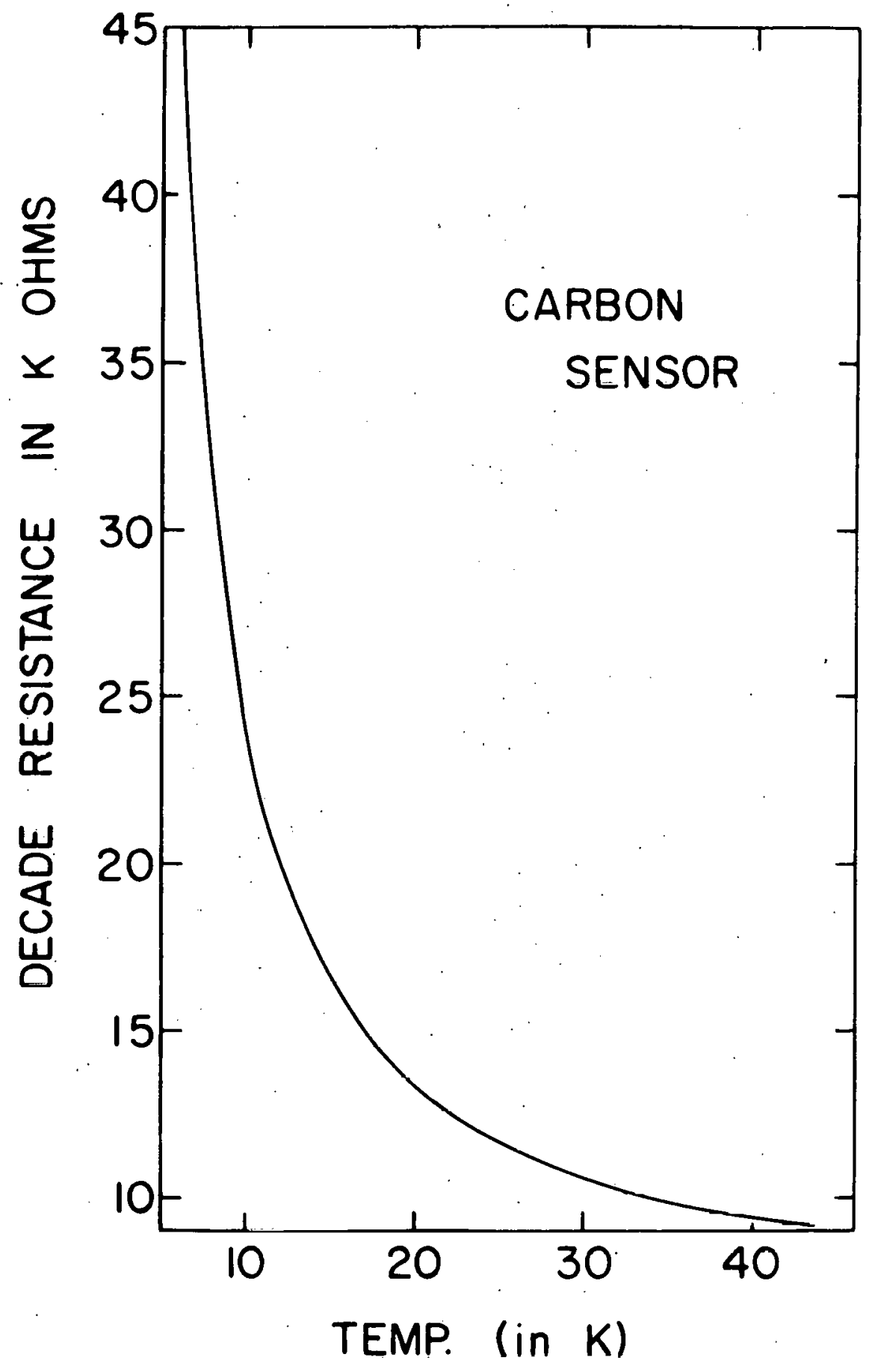


THIS PAGE

WAS INTENTIONALLY

\section{LEFT BLANK}


Figure 5. Decade resistance seztings usəd with copper temperatur sensor. 


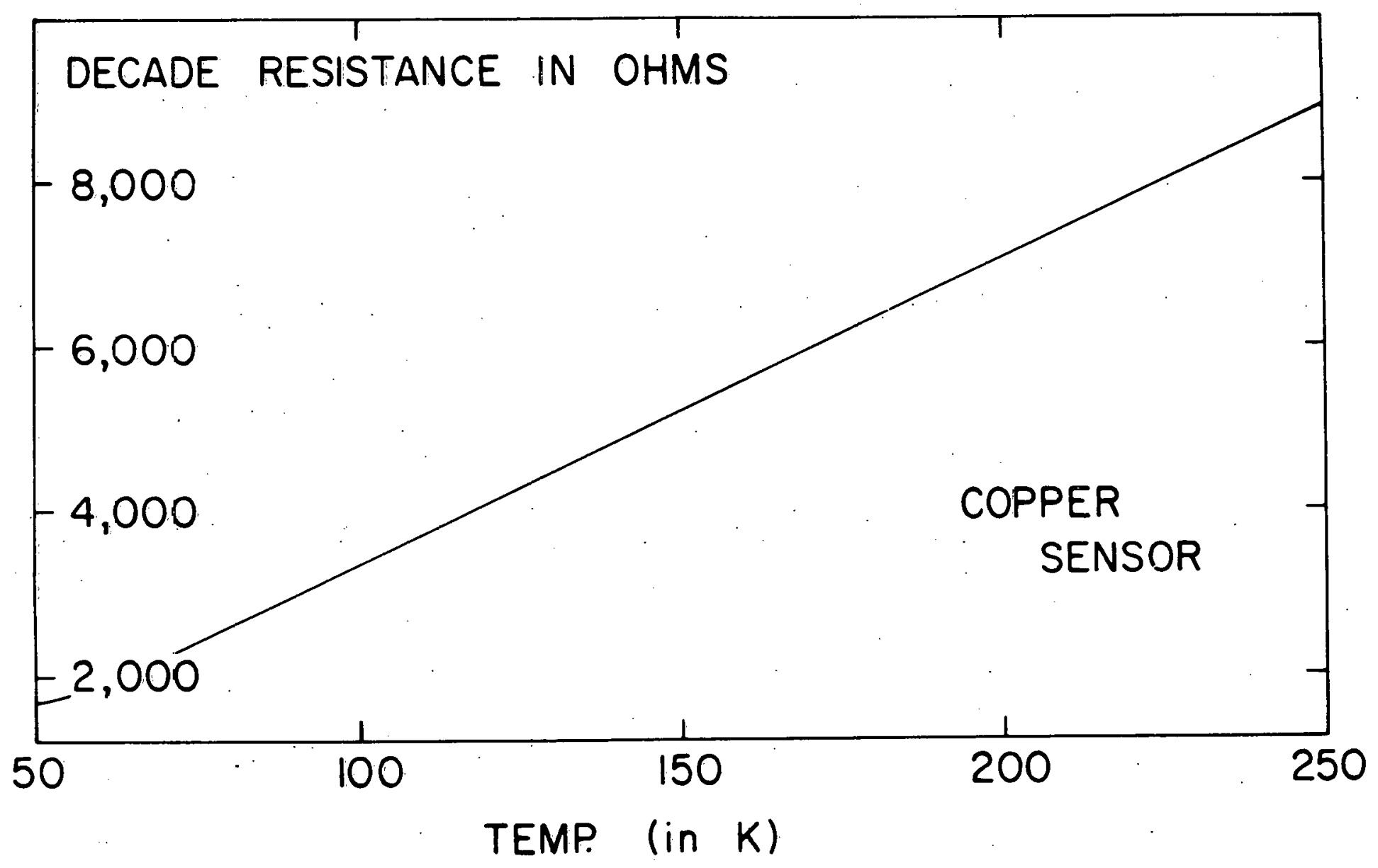


of the sample current. The multi-position switch was needed since the design of the apparatus is such that more than one sample can be measured in succession at each of the temperatures of interest. The resolution of this part of the measurement was $\pm 5 \mathrm{nV}$. It should be also noted that, as seen in Figure 1 , one side of the emf circuit was grounded.

The emf leads in the sample holder were made of No. $36 \mathrm{Cu}$ wire. Because of the delicacy and high impedance of this wire, a change to No. $20 \mathrm{Cu}$ wire at the ice bath was made. The appropriate wires were soldered together and were placed in mineral oil filled glass tubes which were then in thermal contact with the ice bath. The glass tubes give the needed electrical isolation of the varlous junctions.

The other main component of the electronics is for temperature determination. The circuit shown. in Figure 1 is the same as that used by C. F. Eagen (19). The temperature was determined by measuring the voltages of two types of the rmocouples. For temperatures below 30K a $\mathrm{Au}-\mathrm{Fe}$ vs. Cu thermocouple was used. The Au-Fe vs. Cu thermocouple was calibrated using the master calibration of Anderson et al. (20). Anderson et al. have found that below $30 \mathrm{~K}$ any differences between several Au-Fe thermocouples is independent of the temperature. The calibration then consisted in adding a constant emf to Anderson's value at a known temperature. The known point was the boiling point of liquid He at atmospheric pressure.

For temperatures above $30 \mathrm{~K}$ a constantan vs. $\mathrm{Cu}$ thermocouple was used. The master calibration used in this instance is that of 
Sparks et al. (21). The correction is not however of the constant variety as found for the case of a Au-Fe thermocouple. The calibration consisted of using a linear extrapolation method of comparison between two reference points. A total of four reference temperatures were used; the two obvious ones being the boiling points of liquid He and $\mathrm{N}_{2}$. The two other points were $30 \mathrm{~K}$ where the $\mathrm{Au}-\mathrm{Fe}$ and constantan were made to agree and room temperature where there was assumed to be no correction needed.

The thermocouple voltage was measured with a Leeds and Northrup K-5 potentiometer and null detector. This matched component system was able to measure the voltages, and thus the temperature to 0.01 . A Leeds and Northrup low-thermal rotary switch was used to switch between the two thermocouples.

The cryostat was built by Eagen (19), although a large portion of the wiring had to be restrung as a result of grounding problems which developed after extended use. The basic design of the cryostat is shown in Figure 2. It consists of an evacuated heat leak or sample chamber, pump canl, and heaters and sensing clcments for temperature control.

As can be seen, the temperature control centers around a $21 / 8110.0$. Cu pump can. For temperatures above 30K, the pump can is evacuated to limit thermal conduction from the sample chamber to the cryogenic fluid outside the heat leak chamber. The temperature is controlled by passing an appropriate current through a No. 34 manganin heater which was wound 
non-inductively on the pump can. The heater current was determined by a proportional temperature controller that has been described by Mellon (22). The controller is sensitive to the out-of-balance signal from a wheatstone bridge. One leg of the bridge is a non-inductively wound $\mathrm{Cu}$ sensing coil that was wound on the pump can underneath the manganin heater. The sensing coil had a room temperature resistance of 100 ohms.

For temperatures between 4.2 and $30 \mathrm{~K}$ the same manganin heater was used but a 56 ohm carbon resistor was used as the sensing element rather than the copper sensing coil. The carbon resistor was put in thermal contact with the bottom of the pump can with Stycast 2850 epoxy. In both temperature regions the bridge balance point was chosen by a variable resistor in another leg of the Wheatstone bridge. The decade resistance settings used with the two different sensing elements are shown in Figures 4 and 5 . The figures show why each element was used in the two temperature regions described above. The resistance of the carbon resistor varies with the temperature most drastically below 25 or $30 \mathrm{~K}$ while that of the copper coil is large at high temperatures but falls off sharply at low temperatures. The two elements. provide temperature control to $0.01-0.02 \mathrm{~K}$ throughout the region studied.

For temperatures below the boiling point of He the pump can becomes the entire source for temperature control. The pump can was overpressured with He gas and liquid helium was allowed to condense. Normal run times of several hours were achieved with condensation rates of 10 lbs. over-pressure for 10 minutes of helium gas. By lowering the 
vapor pressure over the condensed He the boiling point of the helium was suppressed in such a way that ultimate sample temperatures of $1.5 \mathrm{~K}$ were easily reached. Actually, with a little more time, temperatures of $1.15 \mathrm{~K}$ have been obtained. The vapor pressure was regulated by a manostat which was designed and built by Mr. Marc Pitchford in con-. junction with various vacuum pumps. The manostat controlled the temperature to such an extent that the sample heater and bridge circuit were not used. This allowed for 1-2 hours extra run time from a single pump can of condensed liquid helium, which usually sufficed for each sub-4.2K experiment.

The samples themselves each fit in $3 / 16 "$ slots cut in the side of the sample holder as shown in figure 3. The samples were electrically insulated by means of $2 \mathrm{mil}$ mylar sheets placed between the sample and the sample holder. The mylar was thin enough so that good thermal contact was made with the sample holder. In this manner four samples could be placed in the sample chamber at a time. Due to electrical difficulties two of the slots were not used. The voltage probes were made by Eagen (19). They consisted of phosphor-bronze strips stycast into small Cu bars. The phosphor-bronze strips were sharpened so that they would be like razor blade edges and would make good electrical contact when set in place and held down over the samples with a tantalum spring. The spring was set in the radial notch located in the sample holder as shown in Figure 3. The phosphor bronze "bladesi" were set in a Cu bar so that the sample and voltage probes would have the same thermal expansion. In this way, sample movement under the 
blades was eliminated. The "blades" had their greatest advantage when it came to knowing the length, 1 , between contact points on the sample. Here was a repeatable and highly quantitative procedure for getting 1. Any method of soldering voltage leads to a sample leads to large uncertainties in the resistivity.

\section{Presentation and Discussion of Experimental Results}

The electrical resistivity of the dilute CuCr samples was measured from 1.5 to $80 \mathrm{~K}$ using the procedure outlined above. The actual data points are tabulated in Table $B-1$ of Appendix $B$, while a representative plot of the resistivity vs, temperature is shown in figure 6 . The data above $60 \mathrm{~K}$ are not presented here since it is of no importance to this study. One quite obvious thing should be noted in the high temperature region; the curves for the resistivity vs. temperature for the various samples are parallel. This continues to be true up to $80 \mathrm{~K}$. The low temperature region then shows the kondo effect. The resistivity decreases with decreasing temperature until a minimum value is reached and then increases as the temperature is reduced further. Each of the CuCr alloys shows a well defined minimum. The pure Cu sample, labeled $1.0 \mathrm{ppm} \mathrm{Cr}$ due to spectrophotometric studies, shows no minimum and is exceedingly flat below 20K. As stated earlier, the pure Cu sample had a residual resistivity $(4.2 \mathrm{~K})$ of $7.2 \mathrm{n} \Omega \mathrm{cm}$ which is accounted for by a 6. ppm $\mathrm{Ni}$ impurity content since $\mathrm{Ni}$ impurities produce a residual resistivity of $1.1 \mathrm{n} \Omega \mathrm{cm}$ per ppm in $\mathrm{Cu}(18)$. The temperature at which the minimum in the resistivity occurred was determined for each alloy and 
THIS PAGE

\section{WAS INTENTIONALLY LEFT BLANK}


Figure 6. Resistivity vs. temperature plot showing representative data points for dilute CuCr alloys. 


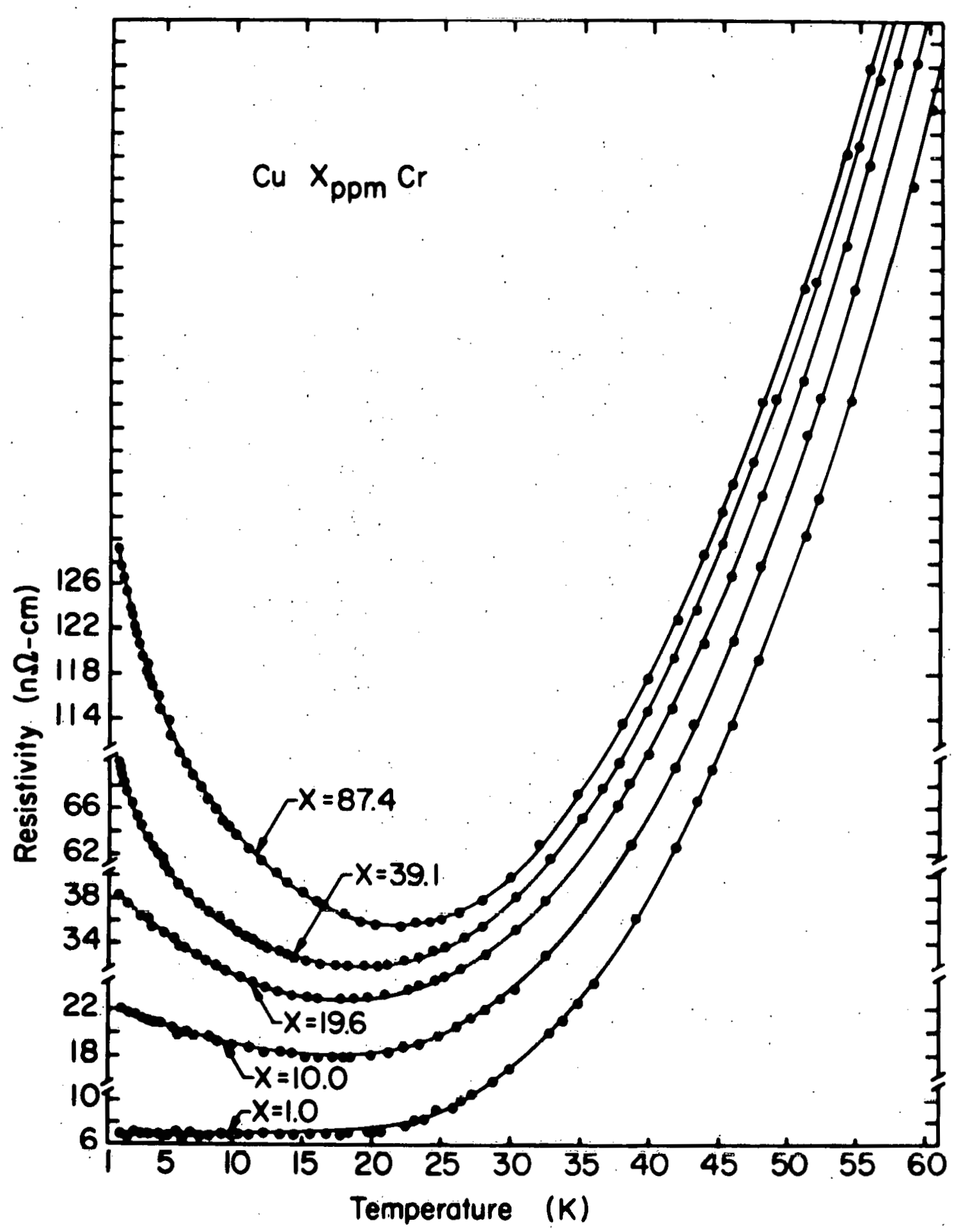


is listed in Table 1 below. The temperature at which the resistivity

Table 1. $\mathrm{Cr}$ content, $\mathrm{T}$ for $\rho \mathrm{min}, \frac{\Delta \rho}{\mathrm{c}}=\left(\rho-\rho_{\mathrm{Cu}}\right)$ at $25 \mathrm{k} / \mathrm{ppm} \mathrm{Cr}$.

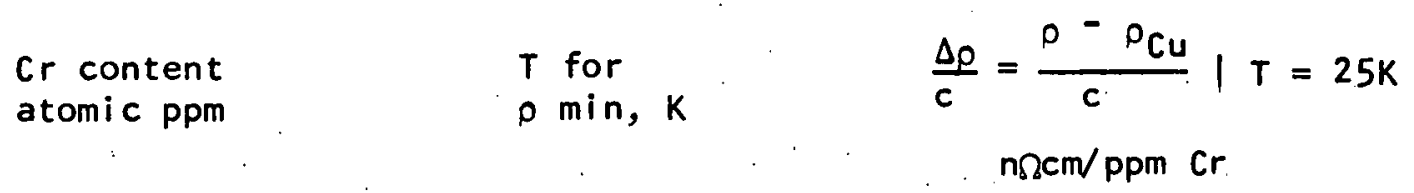

\begin{tabular}{lcc}
$10^{a}$ & 16.0 & 1.13 \\
19.6 & 17.8 & 1.14 \\
39.1 & 19.4 & 1.15 \\
87.4 & 22.2 & 1.00 \\
\hline
\end{tabular}

a This sample was made by arc melting 3 parts pure $\mathrm{Cu}$ with 1 part of the $39.1 \mathrm{ppm} \mathrm{Cr}$ finger. We believe the $\mathrm{Cr}$ content is most reliably taken from this ratio; the chemical analysis of $10.6 \mathrm{ppm}$ was in good agreement with this.

shows a minimum, 'Tmin' was studied as a function of the concentration and of the resistivity at the minimum in order to check the expected behavior as related in the theory section above. There it was shown that

$$
T_{\min }=\left(\frac{3 p_{M} J z}{5 A E_{F}}\right)^{1 / 5} c^{1 / 5}
$$

Therefore, we expected that for CuCr $T_{\min }$ would be proportional to $\mathrm{c}^{1 / 5}$. To check this relation a plot was made of Log $T_{m i n} v s . ~ L o g C$ as shown in Figure 7. To make the data more convincing, the extension to higher concentrations was made by including the findings of Eagen and Legvold (6) on a $114 \mathrm{ppm} \mathrm{Cr}$ in.Cu sample. The least squares method was invoked, and a 
THIS PAGE

WAS INTENTIONALLY

LEFT BLANK 
Figure 7. The temperature of the resistivity minimum is shown to be proportional to the $\mathrm{Cr}$ concentration to the 0.15 power. 


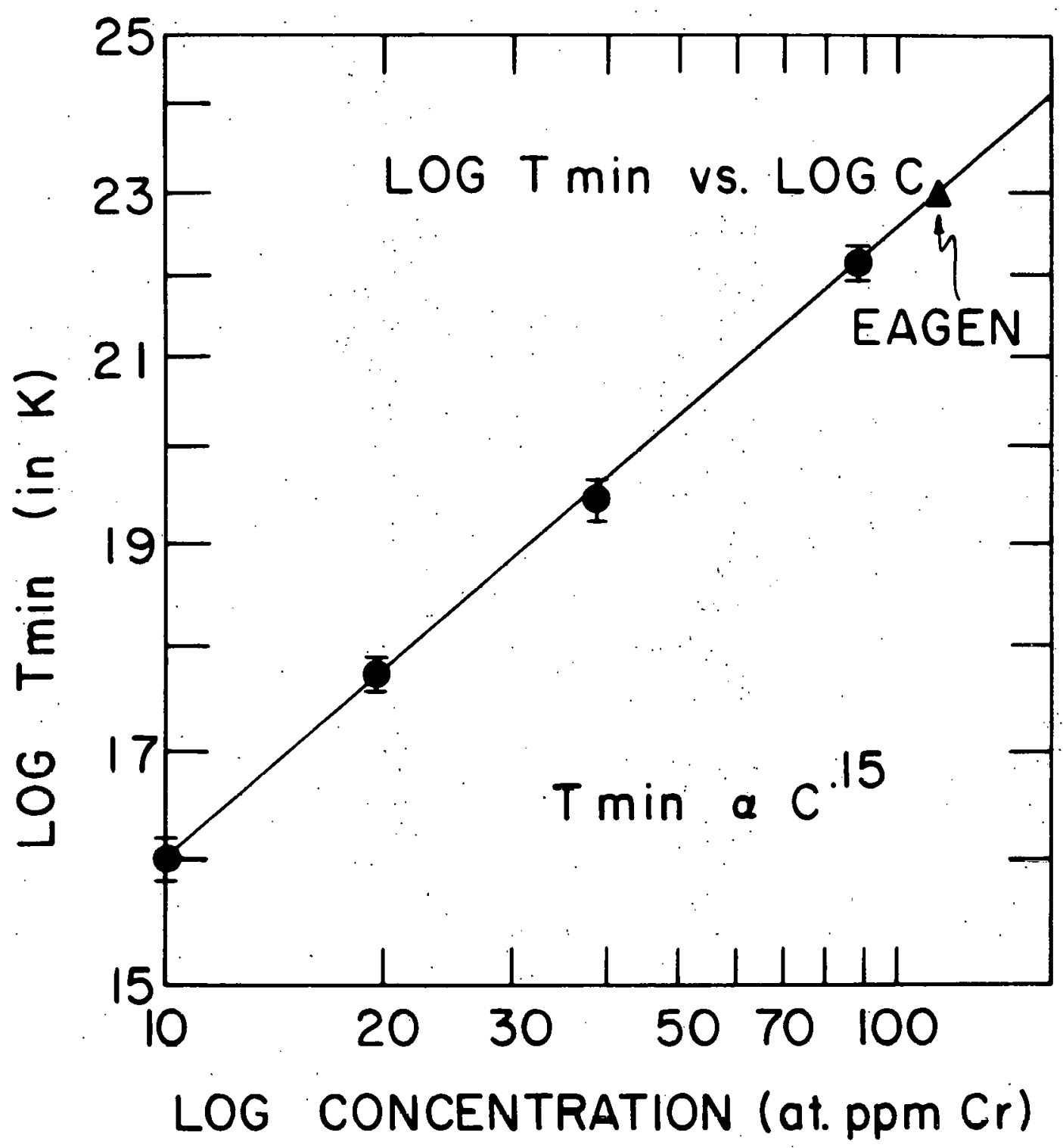


slope of 0.15 was found. It is expected that the resistivity should vary in a Mathiessen's rule manner as a function of concentration. This would imply that $T_{\text {min }}$ should then be proportional to some resistivity value. The resistivity at the minimum was chosen since it is a well-defined parameter and easily determined in this experiment. Another choice might be the resistivity value at which the resistivity stops increasing as the temperature is decreased. This value, could not be determined for these alloys since. it demands temperatures far below those obtained with a simple $\mathrm{He}^{4}$ cryostat. A plot was made of Log $T_{\min }$ vs. $\log \rho_{\min }$ with the inclusion of the Eagen $114 \mathrm{Cr}$ result as before. The result of such a plot is shown In Flgure 8. Here $T_{\text {min }}$ was found to be proportional to $\rho_{\text {min }}$ to the 0.19.power. This then was a first step in studying the minimum in a semi-quantitative fashion. As stated earlier, the system CuFe is found to give $T_{\min } \propto c^{\cdot 19}$. The above result, coupled with that of CuFe, seem to be in agreement with the theory and provided incentive for the further quantitative analyses which follow.

Another point of interest was that of the residual resistivity. To avoid spin flip scattering or Kondo type effects, but still to be in a region of relatively small phonon scattering, the residual resistivity was investigated at $25 \mathrm{~K}$. It has been suggested by Triplett and Phillips (23) that the residual resistivity would be $1.08 \mathrm{n} \Omega \mathrm{cm} / \mathrm{ppm}$ at 4.2K. From evaluation of the slope of a $\Delta \rho$ vs. Log $T$ plot (to be discussed later) an additional shift, $0.3 \mathrm{n} \Omega \mathrm{cm} / \mathrm{ppm}$ at $39 \mathrm{ppm}$ for example, 
THIS PAGE

\section{WAS INTENTIONALLY \\ LEFT BLANK}


Figure 8. The temperature of the resistivity minimum is shown to be proportional to the resistivity at the minimum to the 0.19 power. 


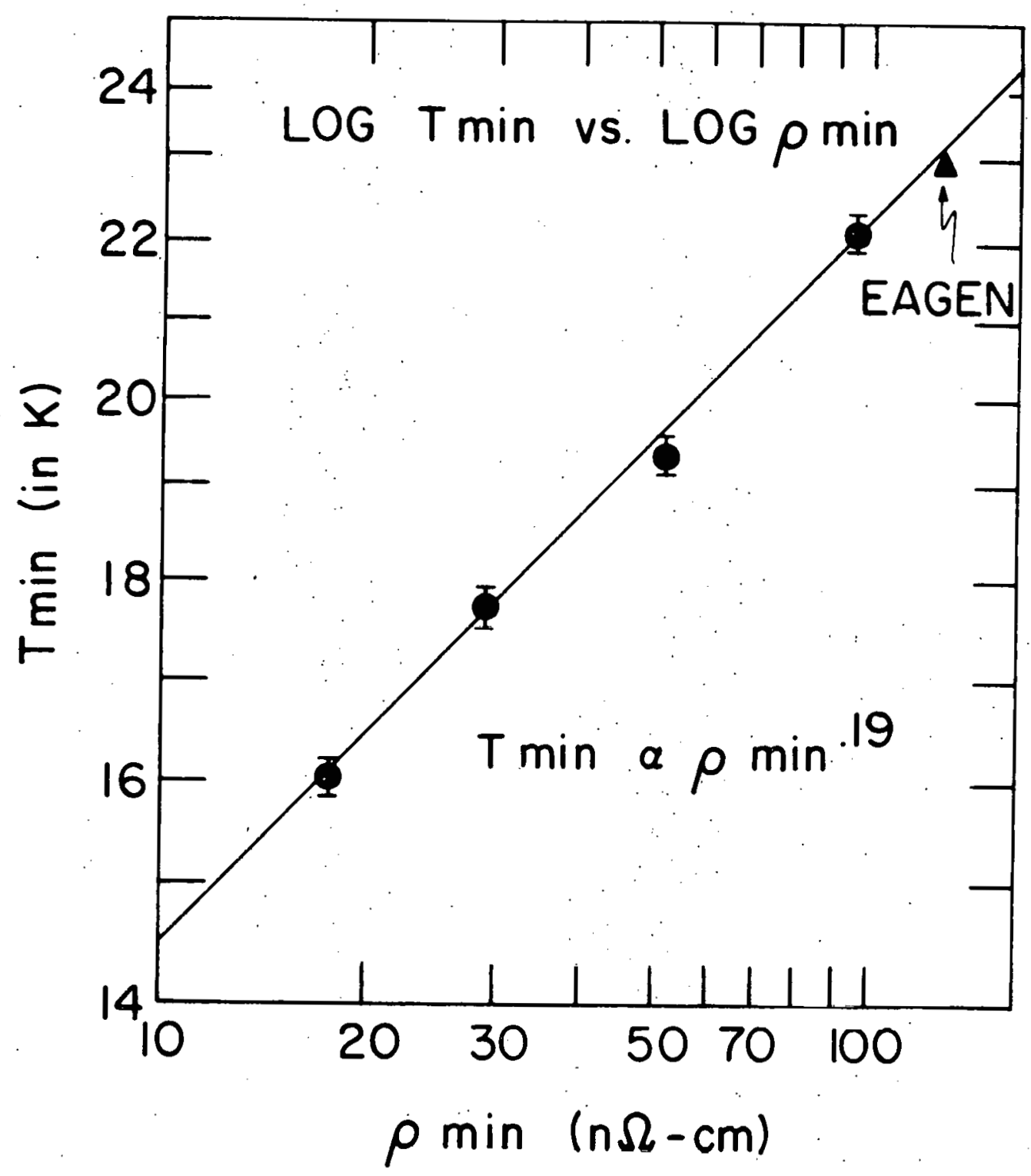


must be made in the $4.2 \mathrm{~K}$ value to get the residual resistivity at $25 \mathrm{~K}$. This procedure suggests that the residual resistivity should be in the vicinity of $0.8 \mathrm{n} \Omega \mathrm{cm} / \mathrm{ppm}$ at $25 \mathrm{~K}$. A plot of the residual resistivity vs. $\mathrm{Cr}$ concentration is shown in Figure 9. We see that the residual at $25 \mathrm{~K}$ was found to be $1.15 \mathrm{n} \Omega \mathrm{cm} / \mathrm{ppm}$ in the limit of zero $\mathrm{Cr}$ concentration. The actual values for $\Delta \rho / C$ versus concentration are given in Table 1 above. The reason for the discrepancy in these two values is not entirely known. The strong, long range, $\mathrm{Cr}-\mathrm{Cr}$ interaction becomes negligible as the $\mathrm{Cr}$ concentration goes below $60 \mathrm{ppm}$. This conclusion arises because the residual resistivity per ppm $\mathrm{Cr}$ increases with decreasing concentration and then levels off in the very dilute regime.

To glean more direct information about $\mathrm{CuCr}$ in terms of a Kondo system, a plot was made of the $\mathrm{cr}$ impurity contribution to the resistivity, $\Delta \rho$, versus Log $T$ for each of the alloys. The pure copper and $39.1 \mathrm{ppm} \mathrm{Cr}$ sample were run at the same time so that $\Delta \rho$ was obtained by direct substraction at each temperature of interest. The following run was made on the 19.6 and $87.4 \mathrm{ppm}$ samples. Since the pure $\mathrm{Cu}$ was not run at the same time, direct subtraction could not be performed. The main reason was that at $4.2 \mathrm{~K}$ there are always non-repeatable cusps due to He condensation on the samples. Depending then on the actual vacuum in the sample chamber, varying size cusps were obtained. The procedure then was to perform the subtractions in terms of a smoothed copper curve which was easily obtainable from the data. The final run was on the $10 \mathrm{ppm}$ sample. The pure copper sample was included so that direct 
THIS PAGE

\section{WAS INTENTIONALLY LEFT BLANK}


Figure 9. $\frac{\left(\rho-\rho_{C u}\right)}{c} \mid T=25 K$ vs. Cr concentration. The difference is taken at $25 \mathrm{~K}$ to eliminate spin-flip scattering effects. 


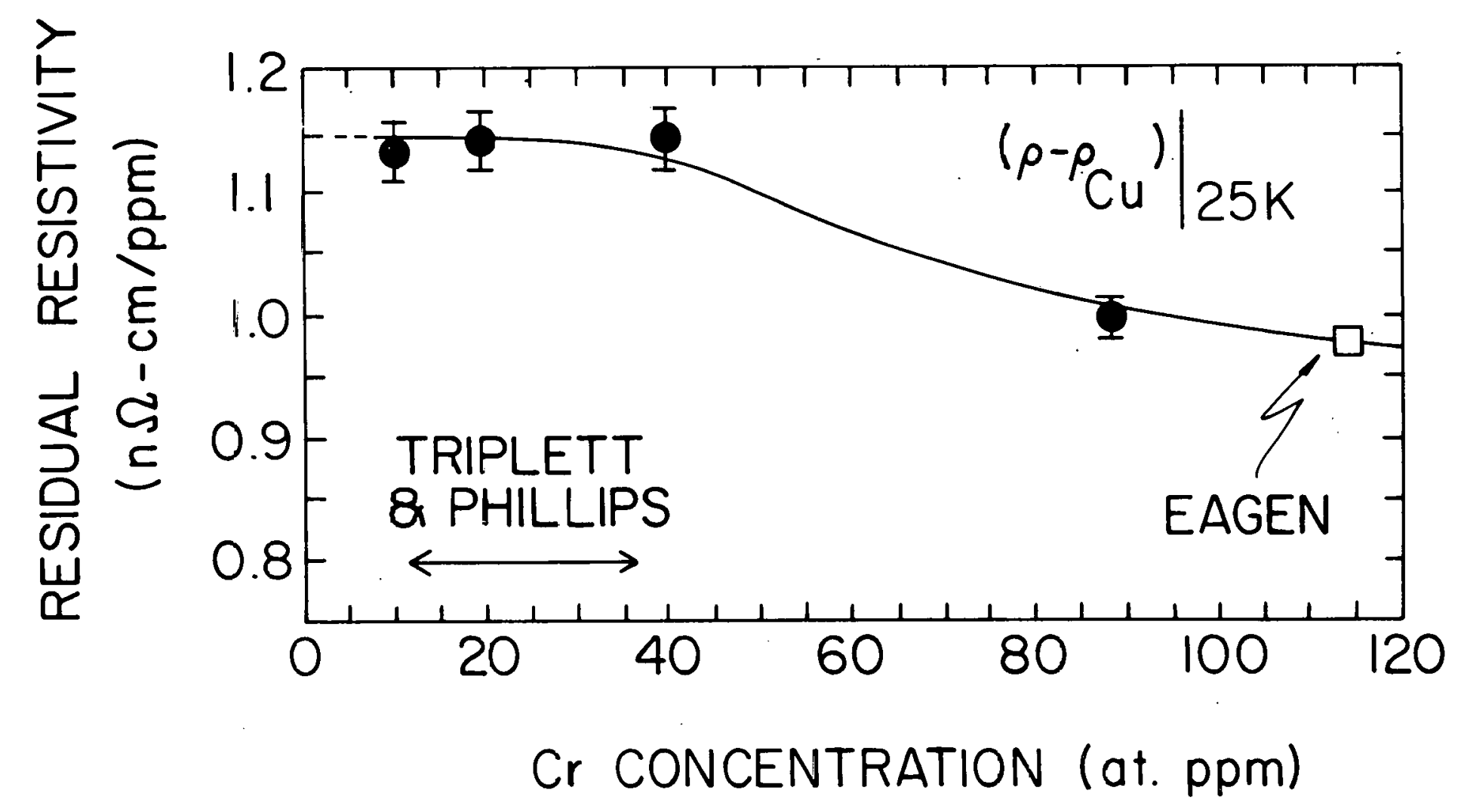


subtraction was again applicable. The subtraction then gave us the $\mathrm{Cr}$ impurity contribution to the resistivity itself since it was. assumed that the resistivity due to the copper lattice was the same in the alloys as it was in the pure copper metal. This seems to be a reasonable conclusion when one deals with such very dilute alloys. As stated above, $\Delta \rho$, the impurity contribution to $\rho$, was then plotted versus Log $T$ (See Figure 10). The reason for doing this goes back to the ideas presented in the theory section where we had the expression

$$
o_{\text {res }}=c_{\rho_{m}}\left[1+\left(3 z J / E_{F}\right) \ln T\right]
$$

For the impurity contribution to the resistivity. Therefore, Kondo's prediction would be that one should find $\Delta_{\rho}$ versus $\log T$ to be a straight line with slope proportional to the exchange integral or constant, J. For ease in presenting the data, all the $\Delta \rho$ vs. Log T plots have been constrained at $2 K$. Each alloy is seen indeed to have the expected straight line behavior on a plot of this type. It should be noted at this juncture that this expected Kondo type behavior was not explicitly found in the work of Daybell and Steyert (5). In this experiment they studied similar alloys by an ac technique. Their data, al though sketchy in this temperature interval and not claimed to be as accurate as ours, did not seem to fit Kondo's prediction very closely. From a casual glance at Figure 10 one notes that the slopes on the $\Delta o v s$. Log $\mathrm{T}$ plot seem to scale according to $\mathrm{Cr}$ concentration. To check this idea, one needs only to plot the reduced slope 
THIS PAGE

\section{WAS INTENTIONALLY \\ LEFT BLANK}


Figure 10. $\Delta \rho$ vo. Luy $T$ plots for the 10, 19.6, 39.1, and 87.4 ppm Cr in Cu alloys. 


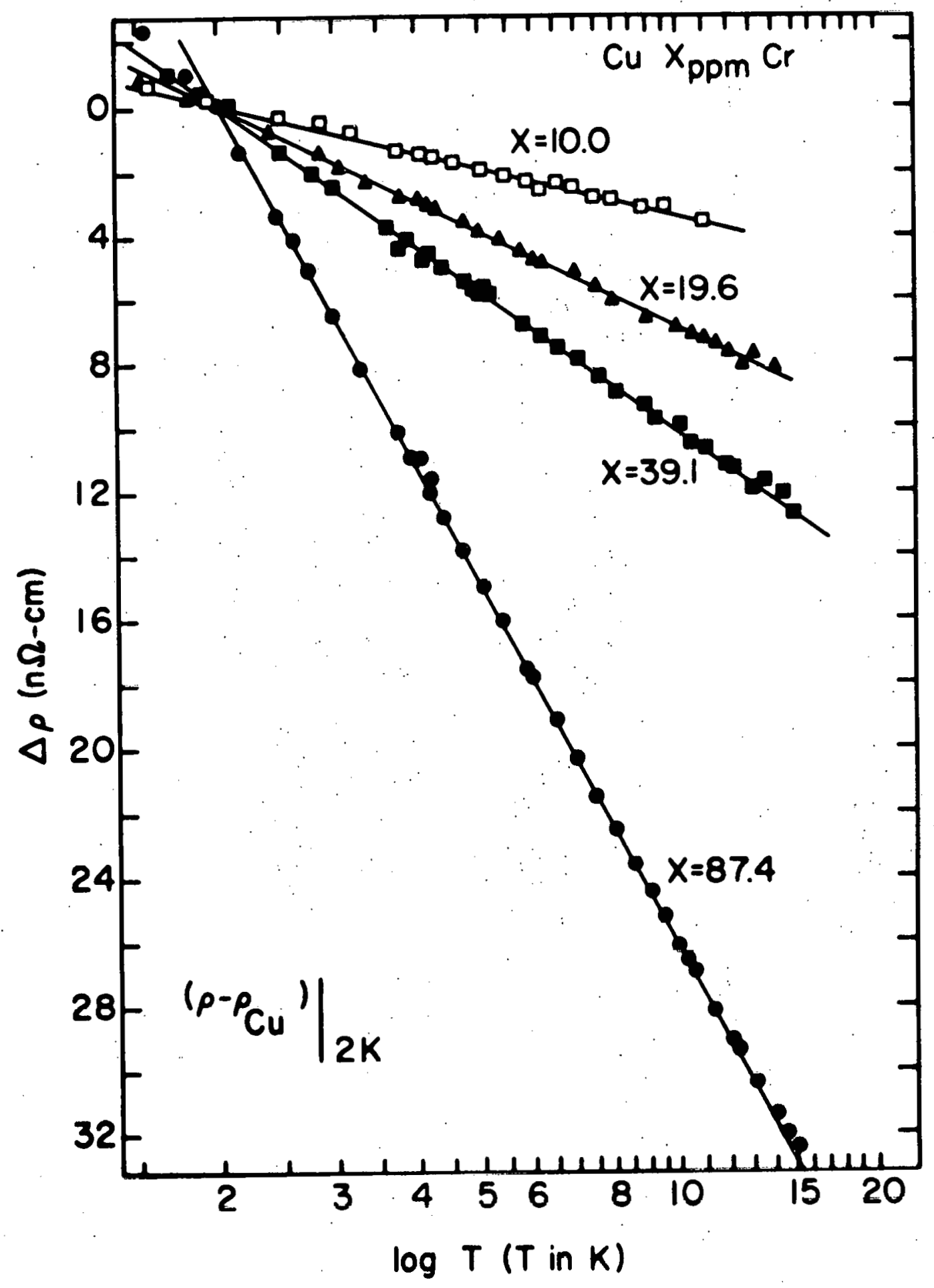




$$
\left(\frac{\rho-\rho C u}{\text { at.ppm } C r \cdot \log T}\right)
$$

versus the chromium concentration in atomic ppm. One would expect that if the chromium ions are indeed non-interacting, the slope vs. concentration plot would be a straight horizontal line. The actual result is shown. in Figure 11. Again the higher concentration results of Eagen are represented by the $114 \mathrm{ppm} \mathrm{Cr}$ result. It may be seen that our results are quite well behaved and show only a gentle linear increase in slope as the alloys became more dilute. The slight increase is indeed consistent with the idea that only in the limit of infinite dilution will the individual chromium ions become totally noninteracting. The gentleness of the slope does reinforce the claim made in all the above that the Kondo expression for the behavior of non-interacting paramagnetic impurities in a non-magnetic host should and does apply to the case of very dilute alloys of $\mathrm{Cr}$ in a $\mathrm{Cu}$ host. The ac results of Daybell and Steyert (5) are presented in Figure 11 also. Their seemingly divergent result for the reduced slope are quite unlike those expected from the general theory. Based on our experience with sample preparation in our first approach, (see sample preparation section) it seems plausible that sample preparation difficulties with $\mathrm{Cr}$ concentration, or the effective location of the $\mathrm{Cr}$ in their samples coupled with their measurement techniques might be of signiflcance in their reported result.

One final bit of information can be found from the slope $d \rho / d \operatorname{In} T$. As found above, this slope should be constant for each alloy and should 


\section{THIS PAGE}

\section{WAS INTENTIONALLY LEFT BLANK}


Figure 11. Slcpes of the $\Delta p$ ve-sus Log $T$ plots of Figure 1 per atomic $\mathrm{ppm} \mathrm{Cr}$ for this work and for the results of Daybell and $S$-eyert (5). 


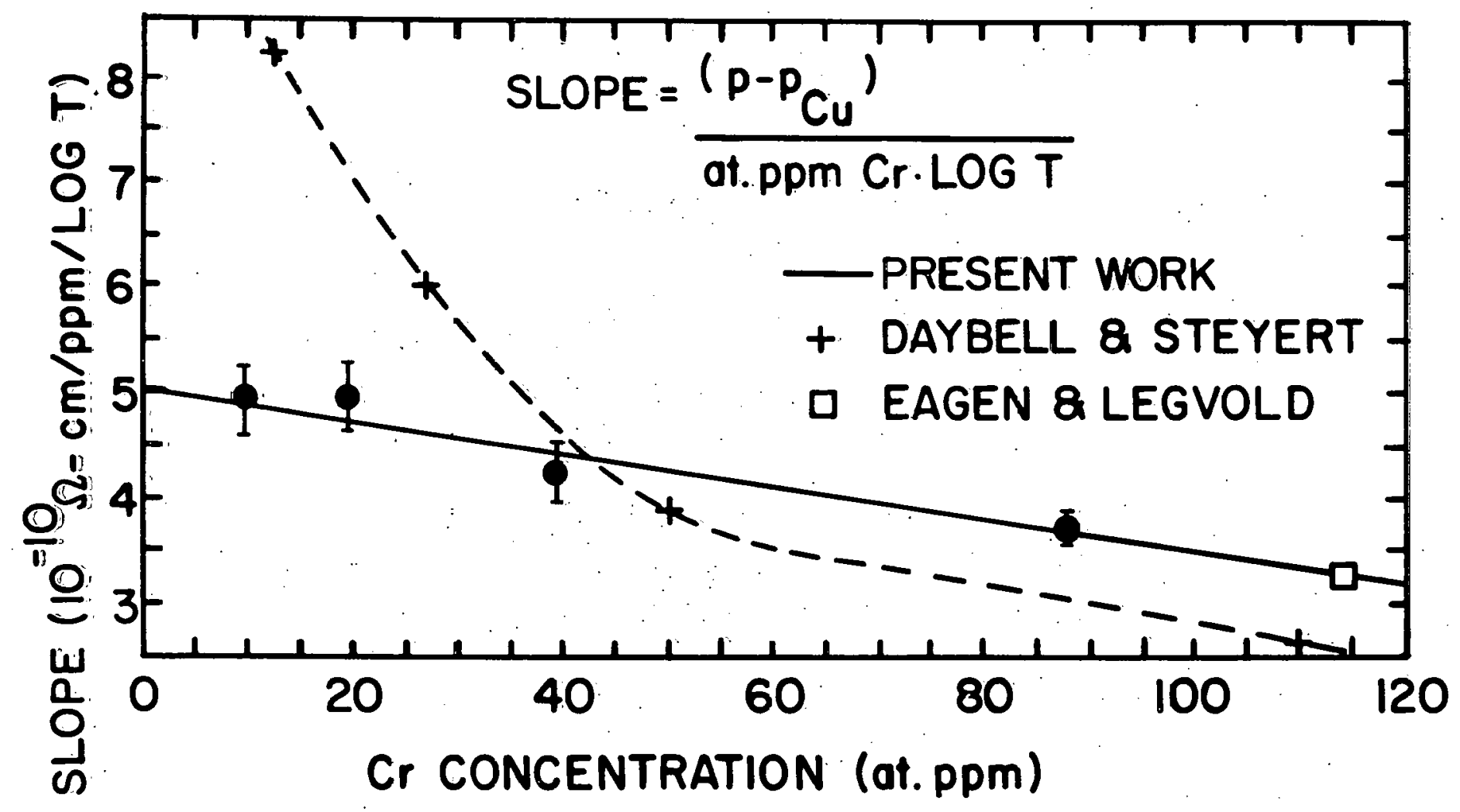


be proportional to the exchange integral or constant, J. We have experimentally determined the slope so we, in principle, have the value of $J$ since

$$
\left(\frac{\mathrm{J}}{\mathrm{E}_{\mathrm{F}}}\right)^{3}=\frac{d \rho_{\text {res }}}{\mathrm{d} \ln \mathrm{T} \cdot \mathrm{C} 69 \mathrm{ZS}(\mathrm{S}+1)}
$$

This result is a direct consequence of finding $d \rho_{\text {res }} / d \ln T$ from

Equation (4) for the impurity contribution to the resistivity for small amounts of impurities in copper. The only problem left is to put in the value for $E_{F}$. Since the alloys were very dilute, the best estimate of $E_{F}$ comes when one assumes $E_{F}=7 \mathrm{eV}$ as for copper.

Taking the values for the slope found from the plots in Figure 10 and plugging this in above along with $E_{F}=7 \mathrm{eV}$ we found values for $J$. (See Table 2). In the limit of infinite dilution, $J \approx-0.6 \mathrm{eV}$.

One is now at the point where another check can be made on the validity of CuCr as a Kondo system and its relation to other systems which seem to also be Kondo type systems.

The first thing to note is that $J$ is found to be negative. This is basic to Kondo's theory since a minimum in the resistivity versus temperature curve results for $J<0$, i.e., antiferromagnetic coupling between the conduction electrons and the localized moment of the magnetic impurity is present. Another criterion is for $\left|\frac{J}{E_{F}}\right|$ to be much smaller than unity. This is an obvious criterion since only then can Kondo's second order Born approximation be a legitimate approach to the problem. From Table 2 one finds $\left|\frac{J}{E_{F}}\right| \approx 0.08$, which satisfies Kondo's criterion reasonably well. 
Table 2. Antiferromagnetic exchange constant $\mathrm{J}$ for $\mathrm{CuCr}$ alloys and a Cu Mn alloy

\begin{tabular}{lccc}
\hline $\begin{array}{l}\text { Cr Conc. } \\
\text { in ppm }\end{array}$ & \multicolumn{1}{c}{ Cucr alloys } & \\
\hline 10 & -0.083 & $J(e V)$ \\
19.6 & -0.085 & -0.58 \\
39.1 & -0.079 & -0.59 \\
87.4 & -0.077 & -0.55 \\
& Cu Mn alloy of Croft et al. (24) & -0.54 \\
40 & -0.075 & -0.53 \\
\hline
\end{tabular}

One comparison which can be made to another so called Kondo system is that to Cu Mn. Croft et al. (24) in 1953 found the straight line Kondo behavior for a plot of $\rho$ vs. In $T$ in the temperature region from $0.007 \mathrm{~K}$ to $4 \mathrm{~K}$ for a $40 \mathrm{ppm} \mathrm{Mn}$ in Cu alloy. He determined $\mathrm{do}_{\mathrm{o}} / \mathrm{d} \ln \mathrm{T}=$ $1.04 \times 10^{-9} \Omega \mathrm{m}$. Using Equation (6) we determined $\frac{\mathrm{J}}{\mathrm{E}_{\mathrm{F}}} \approx-0.075$ for $S=\frac{5}{2}$ which then gives $J \approx-0.53 \mathrm{eV}$ after aydiulassuming $E_{F}=7 \mathrm{cV}$. This seems to be in good agreement with our results for cucr, i.e. $\mathrm{J}=-0.6 \mathrm{eV}$. From extensitive magnetoresistance measurements Monod (25) has found that $\mathrm{J}$ for $\mathrm{Cu} M \mathrm{Mn}$ is approximately $-0.4 \mathrm{eV}$, which agrees quite nicely with the above zero field results. 
Conclusion

CuCr alloys have resistivity minima in the temperature region easily accessible by a $\mathrm{He}^{4}$ cryostat, thus representing a beautiful system for study. The minimum itself is seen to follow the interpretation given to it by Kondo. The resistivity increase below the minimum is due to an indirect exchange interaction between the localized moments due to the impurities and the conduction electrons. The impurity contribution itself shows a $\ln T$ dependence. The temperature at which the resistivity minimum occurs is proportional to the concentration to the power 0.15 which is in good agreement with that derived by Kondo. The values derived from theory and experiment for the exchange integral are negative as demanded by the assumed antiferromagnetic coupling and are of the correct magnitude to substantiate Kondo's second Born approximation calculation. All the information found from the zero field resistivity data implies quite admirably that very dilute CuCr alloys represent a well behaved Kondo system worthy of further study. 


\section{CHAPTER III. MAGNETO-ELECTRICAL \\ RESISTIVITY OF DILUTE CUCr ALLOYS}

Int roduction

In recent years much work has been done on the zero-field properties of dilute solutions of magnetic atoms in non-magnetic metallic hosts. A general review of the historical aspects, as well as recent work, is discussed in the Introduction to Chapter II. Quite an elaborate theoretical frame work has been built up on the subject since 1964, when Kondo introduced the idea that the impurities formed localized moments which interacted with the conduction electrons via the s-d Hamiltonian (4). As explained in Chapter II, Kondo used a second order Born. approximation calculation in his quest for an expression for the impurity contribution to the resistivity. He found that the exchange scattering of the conduction electrons at the Fermi surface by a localized magnetic moment showed a logarithmic temperature dependence. The formalism for the resistivity and its consequences are given in the Theory section of Chapter 11. As described earlier, we carried out experiments on the zero-field resistivity versus temperature characteristics of very dilute alloys of CuCr from 1.5-80K. The alloys contained 10, $19.6,39.1$ and 87.4 at.ppm $\mathrm{Cr}$ in $\mathrm{Cu}$. The results described above are indicative of a well behaved normal Kondo system.

In recent years much effort has gone into the study of the properties of Kondo systems under the influence of external magnetic fields. The theory has been slow in emerging and the conclusions drawn have 
some times been conflicting. To help fill in some of the gaps, we have studied these same CuCr alloys in external fields up to $95 \mathrm{KOe}$. To complement this study, the results of a magnetoresistance study at $4.2 \mathrm{~K}$ in an external magnetic field of $0-85 \mathrm{KOe}$ for a $\mathrm{CuCr}$ alloy containing $114 \mathrm{ppm} \mathrm{Cr}$ will be included. This study by Eagen and Legvold (6) covered the less dilute region of concentrations from 114 to 1,236 at. ppm $\mathrm{Cr}$ and represents. the general extension of this study to higher concentrations.

The present study was done at various temperatures as demanded by our interpretation as to how one arrives at the impurity spin contribution to the magnetoresistance of the alloys. The temperatures chosen were $1.9,4.2$ and $25 \mathrm{~K}$ although a temperature run from 4.2 to $32 \mathrm{~K}$ at $63 \mathrm{KOe}$ was done for the $10 \mathrm{ppm} \mathrm{Cr}$ sample to observe the overall effect of a strong external magnetic field on the resistivity minimum itself, and thereby to check the predicted high field saturation of the magnetoresistance as a function of temperature.

Sketch of the Basic Theory

The effects of an external magnetic field have been worked on most heavily by Beal-Monod and Weiner (26), Moore and Suhl (27) and Bloomfield et al. (28). Two general predictions stand out in their analyses. First, at a constant magnetic field, the resistivity as a function of temperature which results from exchange scattering is suppressed. At high enough magnetic fields the resistivity develops a maximum at temperatures below the minimum temperature. Secondly, 
the resistivity change as a function of magnetic field at a given temperature is negative and saturates in high magnetic fields.

This idea can be explained by a simple argument given by Bloomfield et al. (28) and sketched by Harvey (29): One assumes that the external field is in the $-z$ direction, and one looks at what happens to the impurity spins and the conduction electron spins as the field is increased: The increasing magnetic field can influence the population distribution of each spin system. As the field increases the tendency is for more and more impurity and conduction electron spins to be "frozen out" - to point in the $+Z$ direction. This restricts the scattering of conduction electrons from the spin-up to spin-down state. Therefore, the number of conduction electrons which are spin-flip (Kondo) scattered is reduced. This then causes the resistivity to decrease with field or in other. words for the magnetoresistance to be negative. This partial alignment of impurity spins. is most generally accepted to be a function of $H / T$. As the temperature is reduced below $T_{K}$, this is no longer the case and the magnetoresistance varies more slowly with H. Over the whole range in temperatures, however, the magnetoresistance is negative.

If the magnetic field is large enough, the impurity spins should all be "frozen out" and the magnetoresistance should saturate. BéalMonod and Weiner (26) have shown from third order perturbation theory that this saturation should occur for fields which satisfy the relation

$$
g \mu_{B} H / K_{B} T>4
$$


where $g$ is the gyromagnetic ratio of the impurity spins and $\mu_{B}$ is the Bohr magneton. It has been reported by Yeo (30) that no such effect is seen in CuCr for $g \mu_{B} H / K_{B} T$ as high as 33 at $T=0.1 \mathrm{~K}$ for 200, 350, and 600 at. ppm Cucr samples. This result was tested in the present study for more dilute samples in fields up to 95 K0e. The resistivity should decrease as the magnetic field increases at a given temperature and then saturate or become atmost only weakly field dependent in large fields. Yeo finds experimentally for his three samples that the "resistivity in the magnetic field increases logarithmically with decreasing temperature within a certain temperature range, and that the temperature at which the resistivity becomes temperature independent increases as the field is increased." This disagreement seems to be linked to the problem of including internal as well as external magnetic fields, in non-dilute alloys. We hoped to circumvent these problems by studying very dilute cucr alloys.

To obtain the spin magnetoresistivity at $4.2 \mathrm{~K}$ the normal positive magnetoresistivity due to the alloy itself has to be subtracted off. As shown below; our first attempt was to form the subtraction in terms of the positive magnetoresistivity of pure copper at $4.2 \mathrm{~K}$. This does not take into account the additional positive, and not at all negligible, magnetoresistivity due to the alloy matrix. To get a handle on this, we had to measure the magnetoresistance of each alloy in a region void of much spin-flip scattering and also a region of relatively small phonon contribution. The $87.4 \mathrm{ppm}$ sample had its 
resistivity minimum at a temperature of $22.2 \mathrm{~K}$. For this reason we chose $25 \mathrm{~K}$ as a relevant temperature to get the normal positive magnetoresistivity. ' It is tacitly assumed here that $25 \mathrm{~K}$ is not too high relative to any large phonon contribution. Monod (25) considers the best region to be in the temperature range $15-20 \mathrm{~K}$. It is hoped that our extension of this region to $25 \mathrm{~K}$ is still legitimate. The subtraction then rests on the assumption that the positive term remains constant at low temperatures. Alderson and Hurd (31) have pointed out that this procedure would involve a systematic error. It is assumed that this effect is small. Monod has shown that for a $17 \mathrm{ppm} \mathrm{Fe}$ in Cu sample, this is sufficiently satisfied between 20 and $1.4 K$. Daybell. and Steyert (5) chose $T=21.5 \mathrm{~K}$ in an ac study of the magnetoresistivity of a $28 \mathrm{ppm}$ Cucr sample.

To a fair approximation, the spin magnetoresistivity at $4.2 \mathrm{~K}$ for each alloy versus magnetic field should be found from subtracting the magnetoresistivity at $25 \mathrm{~K}$ from that at $4.2 \mathrm{~K}$. In as far as the above assumptions are correct, we should find a negative magnetoresistance for each alloy at $4.2 \mathrm{~K}$ and some amount of saturation in the magnetoresistivity characteristics as a function of temperature in high external magnetic fields.

\section{Experimental Procedure}

\section{Sample preparation}

The samples used in this study were the same ones used in Chapter 11, Electrical Resistivity of Dilute CuCr. After the zero field 
resistivity study was completed, the samples were cleaned with methyl alcohol and placed under vacuum. Before each run the specific sample was removed and cleaned once more. Just before mounting, the sample was given a light polishing with emery paper in only the areas where voltage probes were to make contact: This gave us the required level of oxide free surface needed to obtain good electrical contact, while leaving the sample area and shape unchanged.

Experimental apparatus

The purpose of this experiment, as mentioned earlier, was to measure the magnetoresistance of dilute CuCr alloys at various temperatures ranging from 1.9 to $32 \mathrm{~K}$ in magnetic fields from 0 to $95 \mathrm{koe}$. The. measurements were made by the standard dc four-probe technique. Two different pieces of apparatus were used in this experiment and both will be described below. The same electronic circuit was used with each apparatus and so this will be described first.

The electronic circuit (see figure 12) consists basically of three parts; one to measure the voltage difference between two known points on the sample, another to measure the temperature of the sample, and still another to measure the applied magnetic field. A list of equipment, its use, and Ames Laboratory equipment numbers used in the electronic circuit are given in Appendix C. A measurement of the current through the sample was not necessary since a current supply was constructed which was stable to better than one part in $10^{6}$. The current used was measured against a National Bureau of Standards resistor to 


\section{THIS PAGE}

WAS INTENTIONALLY

LEFT BLANK 
Figure 12. Electronic circuit used to measure the magnetoresistance of Cucr alloys. 


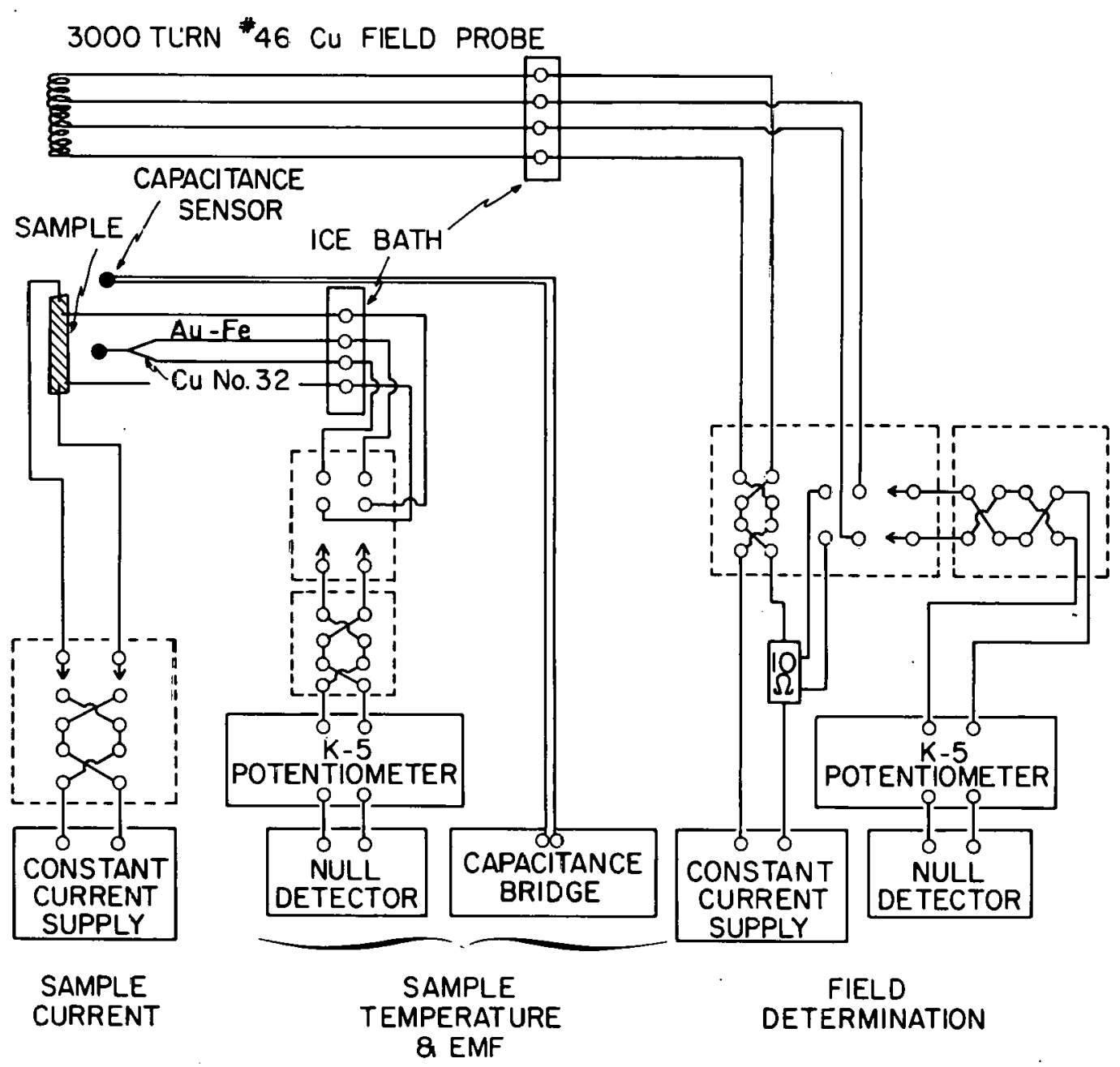


be $149.960 \mathrm{~mA}$ with a temperature coefficient of 2 parts in $10^{7}$ per degree F.

The sample emf was measured by a K-5 Leeds \& Northrup potentiometer. The out of balance signal was observed on a Leeds $\varepsilon$ Northrup dc null detector. This matched set gave voltage measurement capabilities of $\pm 5 \mathrm{nV}$. A Guildline low thermal switch was used to reverse the direction of the sample current while the sample emf polarity was reversed internally to the $K-5$ potentiometer.

The second major part of the electronics is for the determination of the temperature. Since temperatures of interest were less than $35 \mathrm{~K}$ the ultimate temperature measurement relied on a $\mathrm{Au} 0.03$ at。\% $\mathrm{Fe} v s$. Cu thermocouple. The Au-Fe vs. Cu thermocouple in each apparatus was calibrated using the master calibration of Anderson et al. (20). Anderson et al. have found that below $30 \mathrm{~K}$ any differences between several Au-Fe thermocouples is independent of the temperature. The calibration then consisted in adding a constant emf to Anderson's value at a known temperature. The boiling point of liquid $\mathrm{He}$ at atmospheric pressure was used for the calibration point.

The thermocouple voltage was measured with the same potentiometer and null detector arrangement that was used to measure the sample vol.tage. This was accomplished through the use of a Leeds \& Northrup four-pole rotary switch which switched between the voltage probes and the Au-Fe thermocouple. It should be noted al so that the reference junction for the thermocouple was the ice point as was the case for the set-up in Chapter II. 
The temperature could now be determined to $0.01 \mathrm{~K}$ from 1 to $35 \mathrm{~K}$ at zero field, but this experiment was at fields up to $95 \mathrm{kOe}$. This presented a problem, most of the literature tells one that AuFe vs. $\mathrm{Cu}$ thermocouples were inaccurate and unrepeatable in magnetic fields. The first test I performed was to immerse the apparatus without its vacuum jacket directly into liquid He. Knowing the atmospheric pressure therefore gave me the temperature. I took voltage measurements every $5 \mathrm{kOe}$ from 0 to 95 and back to $0 \mathrm{kOe}$ and found the temperature indicated by the junction to be never more than the $0.015 \mathrm{~K}$ different from the original zero field value. There was no upward or downward trend, the variance was perfectly random. The same test was performed on this apparatus twice more with variances of less than $0.01 \mathrm{~K}$ and $0.02 \mathrm{~K}$ for the two tests. The second apparatus had a similar junction location and voltage characteristic. Here again, variances less than $0.02 K$ and $0.025 K$, were found under the same test conditions. I am therefore confident that when a properly cycled, both thermally and magnetically, AuFe vs. Cu thermocouple is placed in an apparatus as will be shown below, and specifically in my case, the temperature can be measured to $\pm 0.03 \mathrm{~K}$ at fields up to $100 \mathrm{KOe}$. It will be seen that for this particular experiment $\pm 0.03 \mathrm{~K}$ is of sufficient accuracy. It should be noted that a similar long time, zero field, test of a Aufe thermocouple proved to be of nu greater accuracy than $\pm 0.015 \mathrm{~K}$ which makes my non-field dependent proposal look even better. 
Because of the supposed field dependence of AuFe thermocouples, arrangements were made in each apparatus for a temperature sensitive capacitor' (the CS -400 Cryogenic Capacitor by Lake Shore Cryotronics, Inc. Eden, $N_{0} \dot{Y}_{0}$ ) to be used to monitor the temperature and to be used as a non-field dependent sensor to regulate a heater supply. The capacitance is measured by and used to run the heater supply furnished by the Model CSC -400 Cryogenic Capacitance Controller built by Lake Shore Cryotronics. Since this section is on temperature determination, I will restrict my discussion here to the capacitance sensor as a temperature determination device.

The first lesson to be learned with this sensor is that stray ac signals restrict its accuracy drastically. For this reason the leads to the sensor from the capacitance bridge had to be coax. In the cryostat itself the coax had to be small due to heat leak and size restrictions. The coax used was Lake Shore Cryotronics 50 ohm Ultraminature Coaxial Cable type M. When cooling down, the leads to the sensor must be shorted together. Instability times are increased to hours if this is not done during cool down. Once the capacitor is sitting at an initial constant temperature, say $4.2 \mathrm{~K}$, it takes upwards of an hour or more to settle in to a fairly constant capacitance value. During the experiments to be described later, the sensor was monitored along with the Aufe thermocouple with the following results. Figure 13 and 14 show typical capacitance versus temperature response curves taken after long initial stablization periods for sensors \#247 and \#248, 
respectively. It must be noted that the capacitances given are those of the sensor plus a variable trimming capacitor built into the bridge. In this way one can in theory find a universal response curve for each sensor and then use a single calibration temperature and the trimming capacitor to essentially recalibrate the sensor over the whole region of interest each time. In Figure 13 we see the response of one of the sensors near the boiling point of liquid helium. The response is parabolic and fairly well behaved. In Figure 14 we again see the parabolic response but this time over a much larger range of temperatures. From these plots one gets the impression that these sensors should be capable of $\pm 0.005 \mathrm{~K}$ temperature determination. The catch here is that these plots were made over very short periods of time with intermediate recalibration. This can, of course, not be done during an experiment. It does show that these sensors are very well behaved if one can subtract out or in some other way compensate for temperature implied drifts in capacitance on the order of $1 \mathrm{k}$ over one or two hours near $4.2 \mathrm{~K}$.

For this reason the capacitance sensor could not be used for the major determination of the temperature. The stability of the sensor over short periods of time made it valuable when the sample emfs were being taken as a monitor on the temperature al ready determined by the AuFe vs. Cu thermocouple. It was also extremely useful in temperature control, as will be explained below, when the field value was belng changed as well as under constant field situations. 
THIS PAGE

\section{WAS INTENTIONALLY \\ LEFT BLANK}


Figure 13. Capacitance vs. temperature plot for sensor $\$ 247$. 


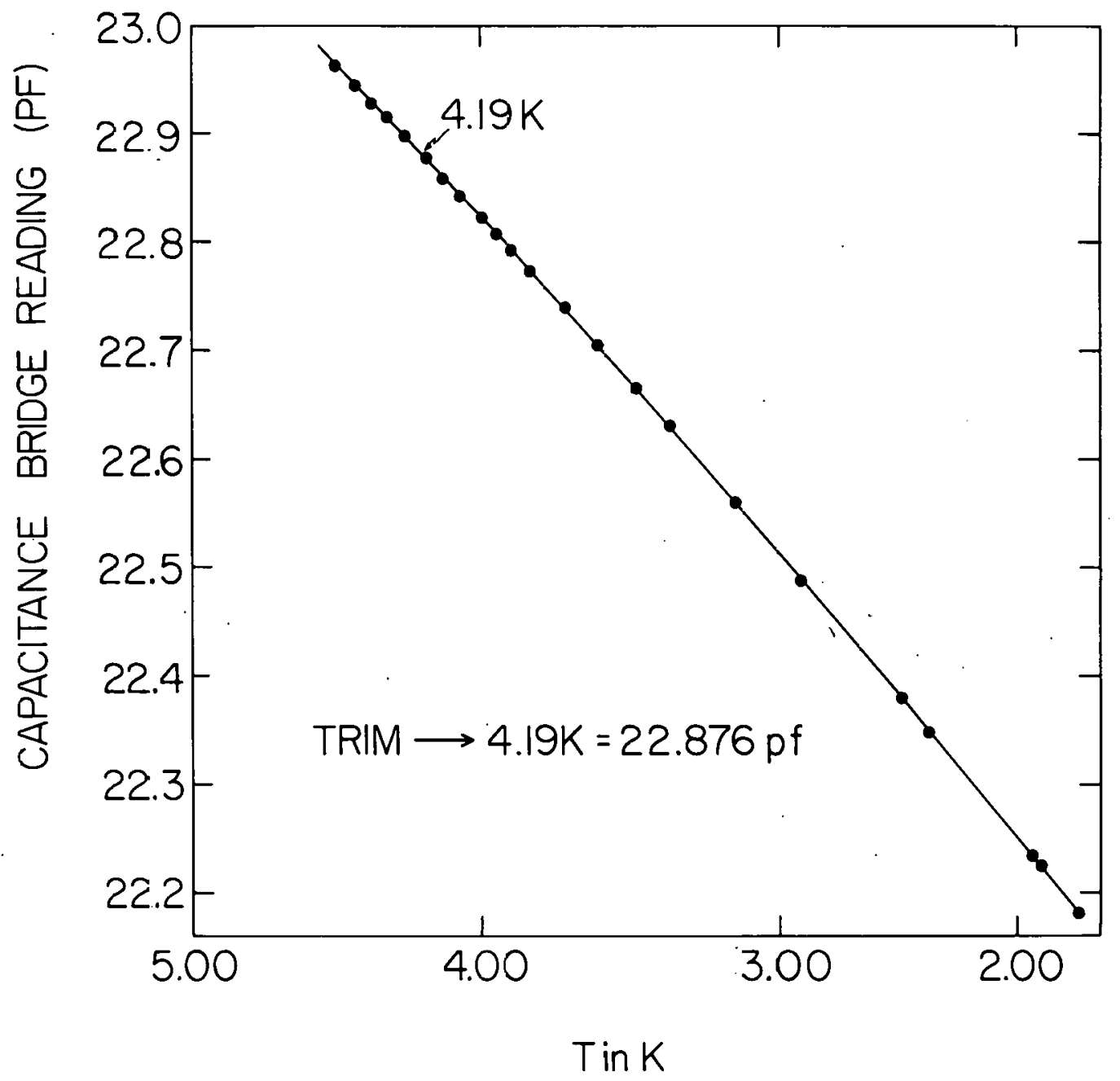


THIS PAGE

\section{WAS INTENTIONALLY \\ LEFT BLANK}


Figure 14. Capacitance vs. temperature plot for sensor \# 248. 


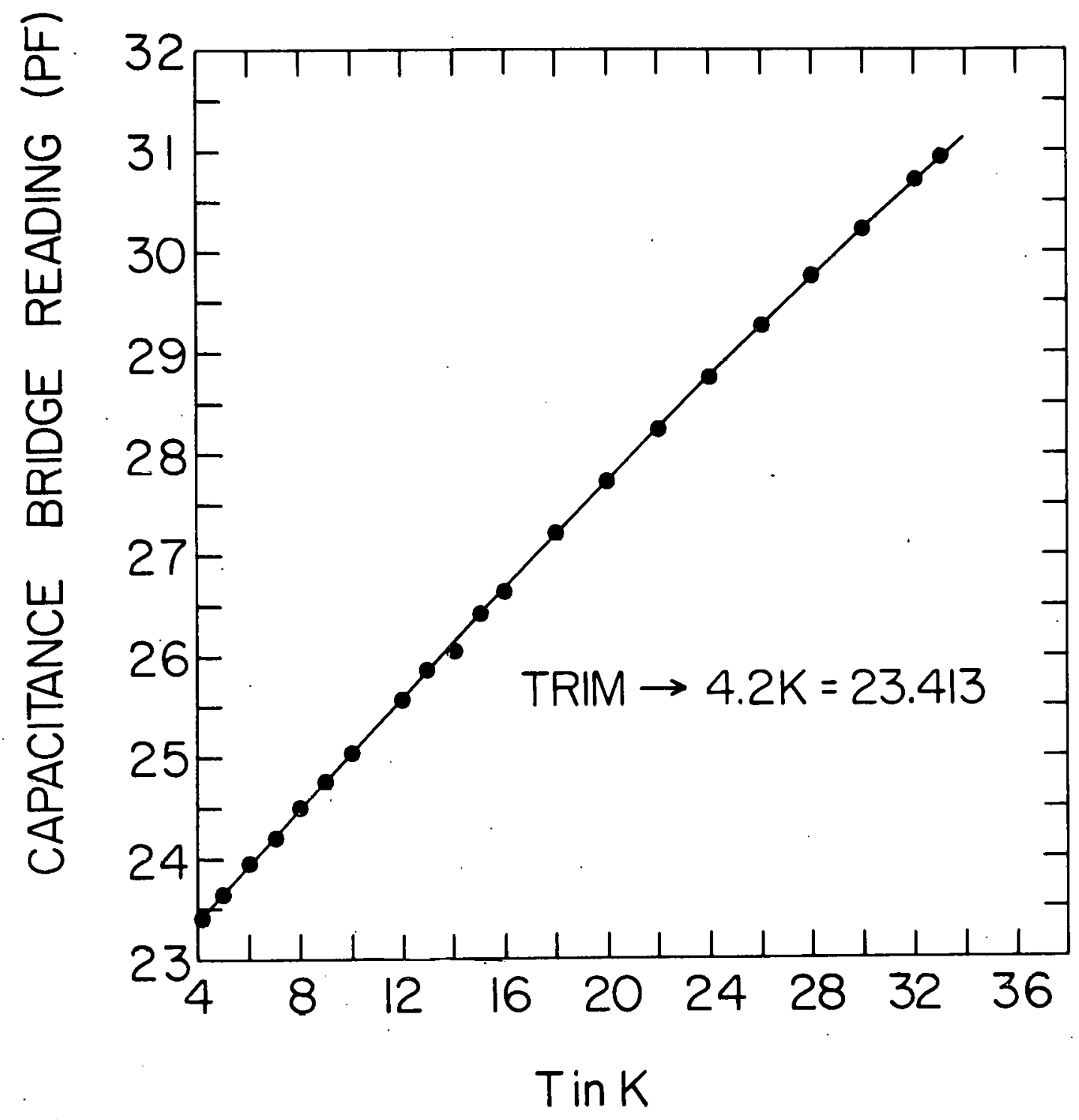


The final major part of the electronic circuit was the determination of the applied magnetic field. The magnetic field was supplied by an RCA Superconductive Magnet Type SM2804 which was fabricated using RCA SR-2100 and SR-2101 Nb 3 Sn superconductive ribbon. Solenoids wound with $\mathrm{Nb}_{3} \mathrm{Sn}$ show marked hysteresis. When the solenoid was driven to full field ( $95 \mathrm{KOe}$ in this experiment) and then brought back to a zero current input configuration, it was found to maintain a residual field of 5 or 6 kilogauss at the center of the solenoid. For this reason the current could not be used as an indication of the field at the center of the solenoid. It was therefore necessary to measure the magnetic field directly. The method for doing this may be found in the Ph.D. thesis of Dr. Durkee Richards (32). Essentially, the procedure is as follows; a coil of 3000 turns of number 46 thermocouple grade copper wire was wound astatically on a glass base phenolic resin form. The coil was placed between the coil form and the bore of the magnet. The magnetoresistance coil was calibrated against a small pure copper coil which was in turn calibrated against an N.M.R. gaussmeter in a high homogeneity $60 \mathrm{kilo-0ersteds} \mathrm{solenoid.} \mathrm{It} \mathrm{was} \mathrm{found} \mathrm{that} \mathrm{the}$ resistance of this probe was linear above 4 k0e out to $60 \mathrm{koe}$. In this way the magnetic field can be read to the nearest 100 oersteds.

The field can thus be found by merely measuring the magnetoresistance of the coil. As seen in Figure 12; the resistance of the coil was measured using a K-3 Leeds \& Nöthrup potentiometer and matched null detector again utilizing the standard de four-probe technique. 
The current through the coil was measured by reading the voltage across a 1 ohm standard resistor with the same set-up by means of a Leeds $\varepsilon$ Northrup rotary switch. Using this method the magnetic field is estimated to be known to 100 oersteds below $60 \mathrm{k0e}$ and to have an overall accuracy of better than $\pm 0.5 \%$ up to $100 \mathrm{KOe}$ 。

One final subject must be mentioned before concluding this electronics sections. This is the subject of temperature control of the sample holder. Each apparatus had the same heater arrangement for obtaining temperatures above $4.2 \mathrm{~K}$. The basic idea was to use a $160 \mathrm{ohm}$ manganin heater as a large bulk heater supplemented by a 10 or 12 ohm trimming heater. The bulk heater was regulated by monitoring a 56 ohm carbon resistor thermally grounded to the sample holder. The details of the bridge and heater current supply are the same as those given in Chapter 11 . The trimming heater was regulated by the capacitance of the capacitance sensor. Here then is the versatility of the capacitance sensor. Each fixed temperature is determined by the Aufe thermocouple and regulated by the two combined heaters. When the field changes llie carbon resistor characteristics are uncertain but the trimming heater adapts to any changes since the capacitance sensor is not field dependent. This provides for constant temperature and long equilibrium times under any field conditions. Equilibrium times under constant temperature situations are therefore unimportant so that the time betwe:en measurements is only dependent on the time for the field to stabilize. Therefore, although the capacitance sensor was not 
found reliable for temperature determination, it was indispensable. in terms of temperature control and stability.

Before the cryostat could be designed several significant variables were considered. The most obvious was in deciding where the sample should be placed in the solenoid so that the field would be uniform across the sample. Figure 15 shows the field measured at various points on the axis of the solerioid. The sample region was roughly $3 / 4$ ', so the sample holder had to be built in such a way that the center of the sample was 0.4 inches above the center of the solenoid. Another consideration was in the height of the working area above the solenoid. We wanted to make this region easily workable in size but wanted it to be in liquid helium over as much of the run time as possible. The helium level in the dewar was monitored by a Westinghouse liquid level indicator which was calibrated in a 50 , storage dewar. The main dewar was found to have a liquid helium level as shown in Figure 16. Here we see that even for an extravagantly lossy transfer the level obtained is still only 11 inches above the solenoid. This meant that the working region should be kept under 6 inches above the solenoid.

The next section will be a brief description of the two cryostats used in this experiment. The first was designed for work below and slightly above 4.2K. The sample region is shown in Figure 17. For temperatures below $4.2 \mathrm{~K}$ liquid helium is condensed or admitted into the pump can and the vapor pressure above the liquid is regulated by a manostat. The temperature can be regulated in this way to $\pm 0.02 \mathrm{~K}$ or better depending mostly on need. All wires except the emf, AuFe 
THIS PAGE

\section{WAS INTENTIONALLY LEFT BLANK}


Figure 15. The on-axis nagretic fielld measured at various places relative to the center of the solenoid. 


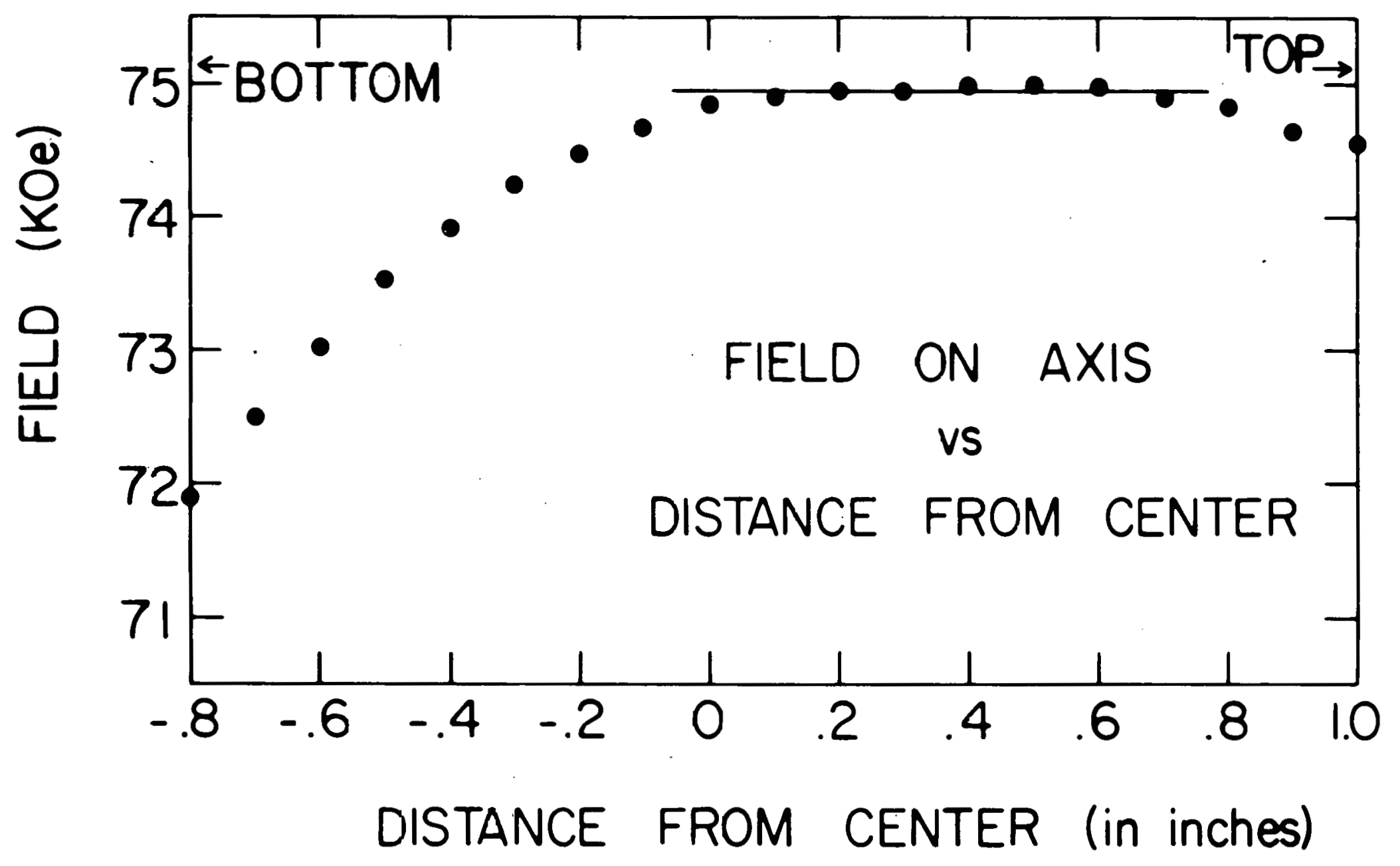




\section{THIS PAGE}

\section{WAS INTENTIONALLY \\ LEFT BLANK}


Figure 16. Helium level in dewar as measured in relative percentage units on a Westinghouse liquid level indicator. 


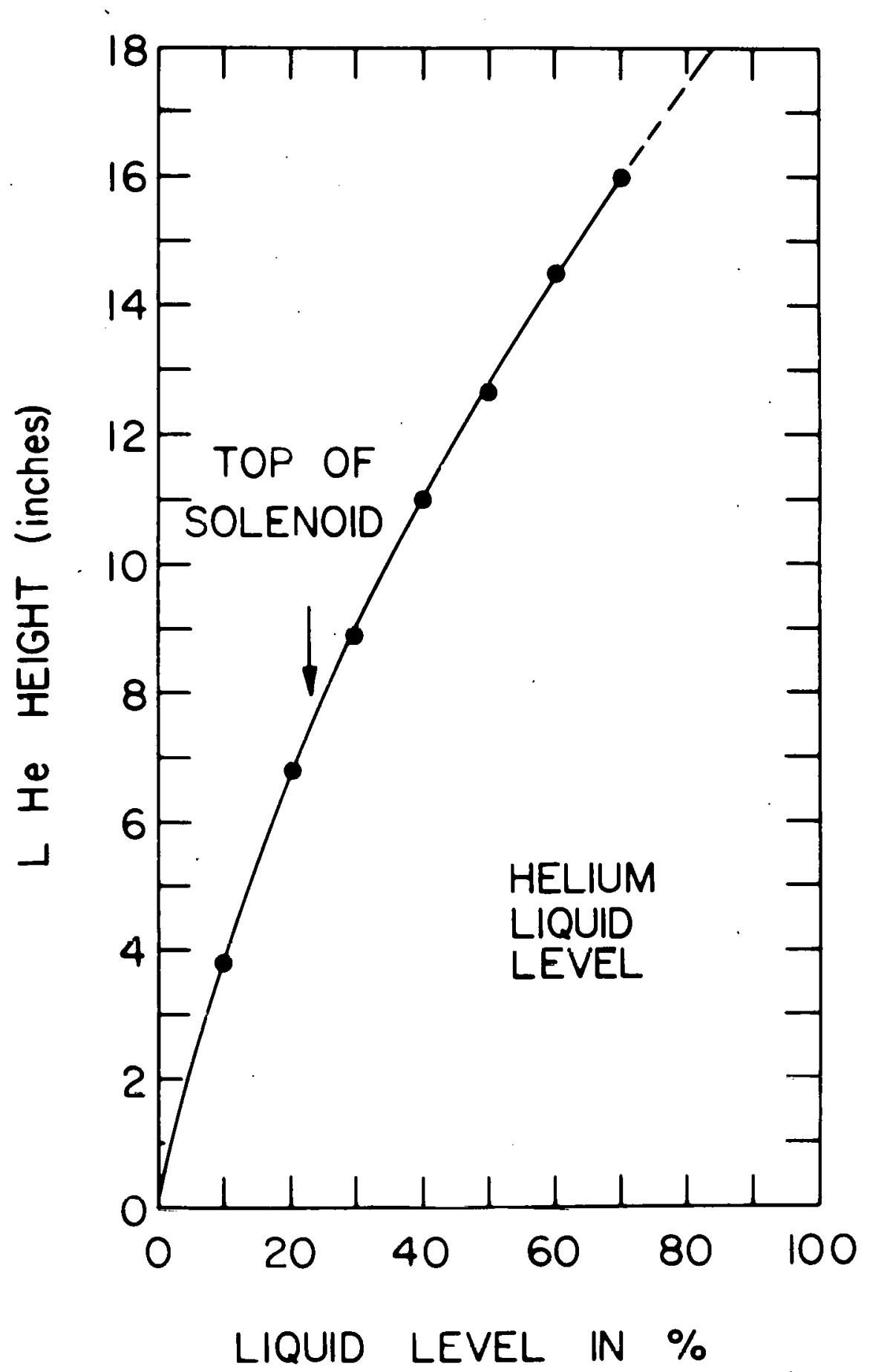




\section{THIS PAGE}

\section{WAS INTENTIONALLY \\ LEFT BLANK}


Figure 17. Sample holder \#1 used in CuCr magnetoresistance measurement below and above $4.2 \mathrm{~K}$. 


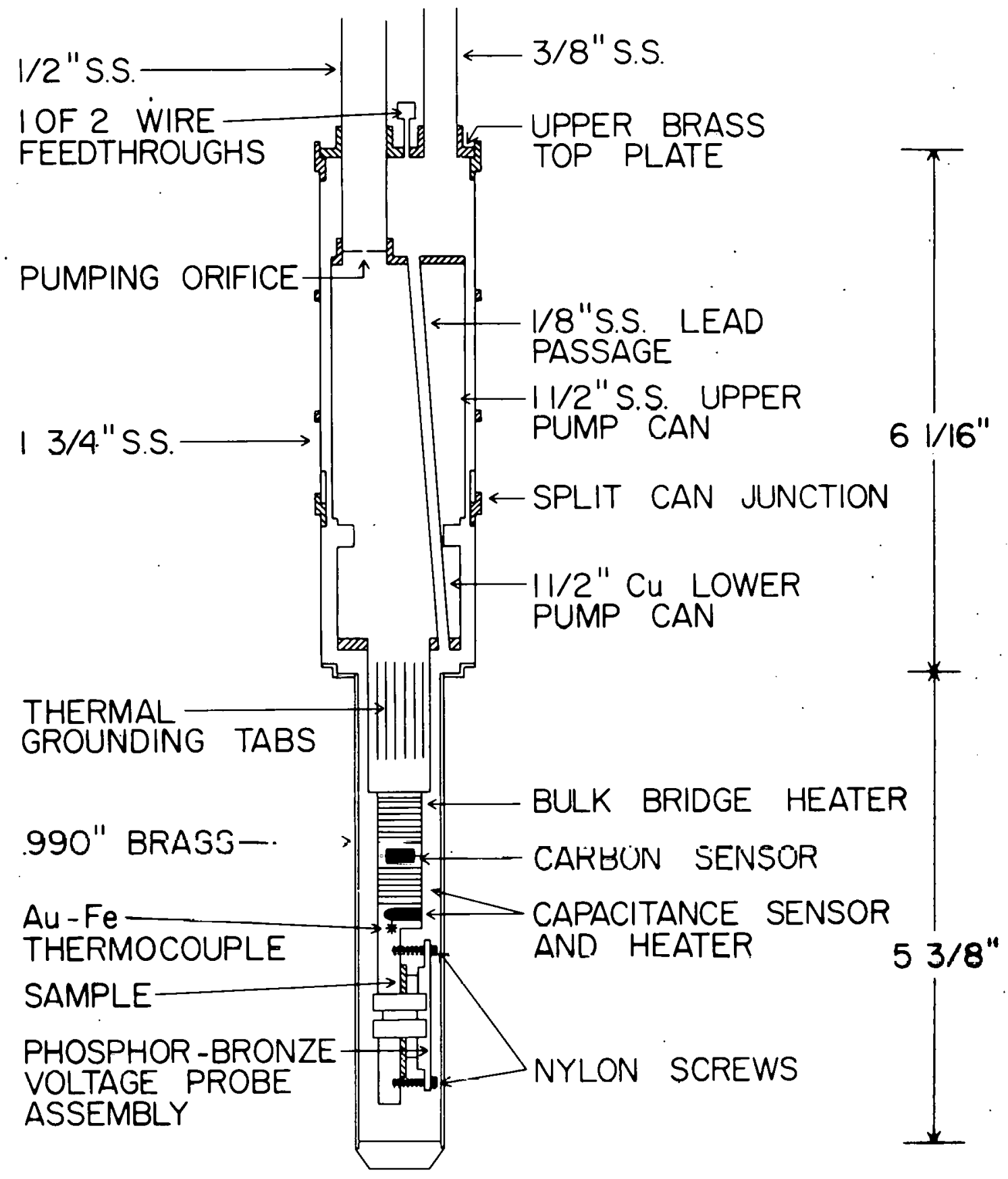


thermocouple and coax to the capacitance sensor terminate on the thermally grounded copper tabs above the measuring region. The AuFe thermocouple is mounted vary close to the sample by thermally grounding it in a hole in the side of the sample holder itself. The heaters are located in the positions shown so that the trim heater is on the sample side of both the pump can and bulk heater, enabling it to control the ultimate sample temperature. The voltage probes are made of phosphorbronze and mounted in a copper bar. They are held on the sample by nylon screws located as shown. A more detailed explanation of the probes is given in Chapter 11 where a similar arrangement was used.

Figure 18 shows the position of sample holder \#l in the dewar relative to the top plate and solenoid. In this diagram can be seen various parts yet to be mentioned. The most important is the liquid helium manual fill system. This system enables one to open and close a needle valve from the outside which will admit liquid helium into the pump can directly, without the need to over pressure as was required in the apparatus used in Chapter 11 for the zero-field study. This enables one to refill the pump can while the vapor pressure over the liquid helium in the can is being controlled by the manostat. Therefore one can keep the sample holder at $1-2 K$ for extended periods of time.

Also shown in Figure 18 are the copper baffles attached to the stainless steel magnet support rods. These retard the cold helium yas from leaving the bottom of the dewar quite so quickly. This helps significantly with the liquid helium loss problem. Also depicted in 


\section{THIS PAGE}

\section{WAS INTENTIONALLY}

LEFT BLANK 
Figure 18. Complete scheme for the use of sample holder \#1 including its position in the dewar and in the superconducting solenoid. 


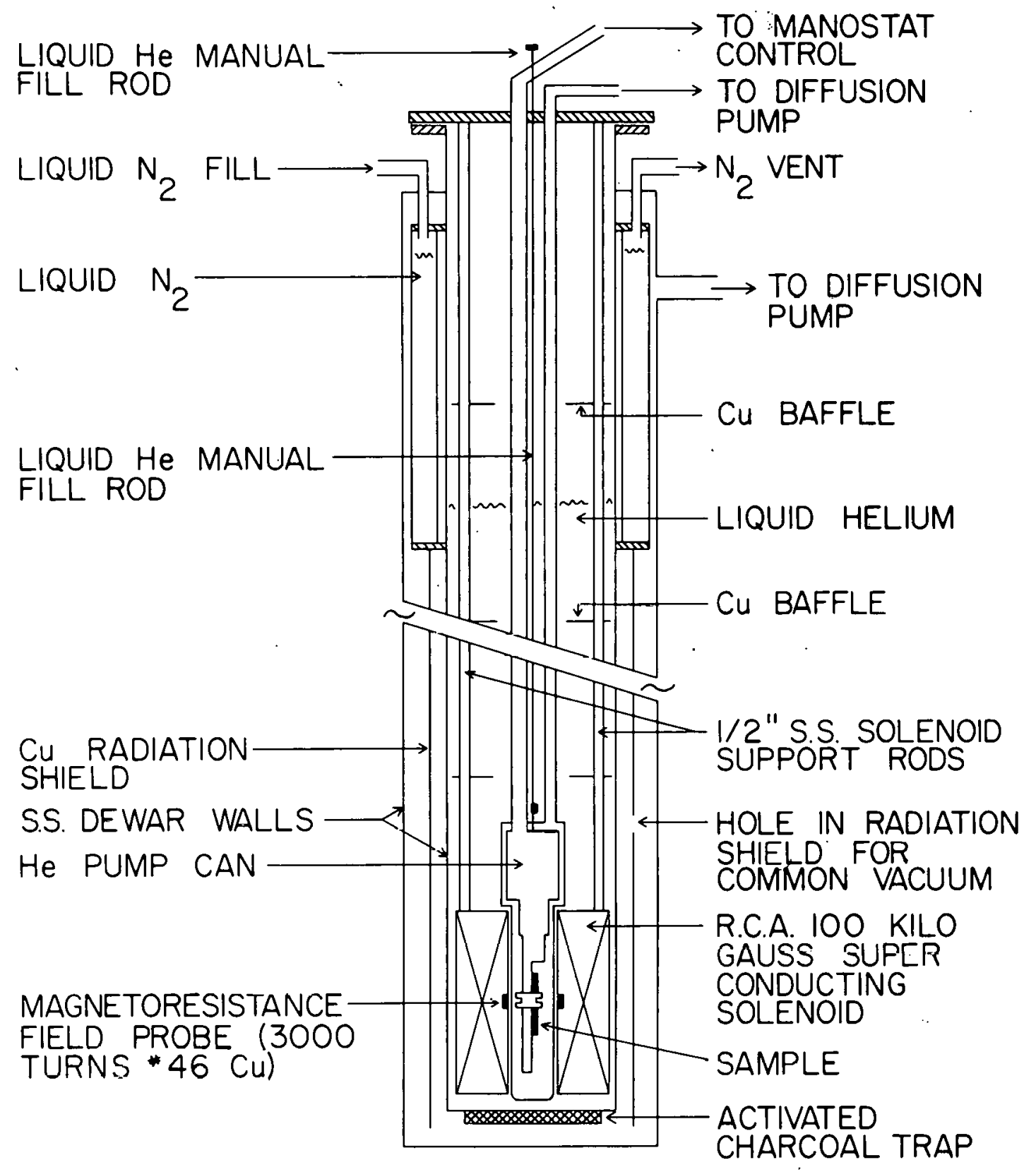


the diagram is the general construction of the dewar, with its vacuum and liquid nitrogen jackets as shown. Another apparatus was built without the sub-4.2K capabilities but one that could reach temperatures of at least 50K. The apparatus is shown in Figure 19. The apparatus consists of a single pump line to evacuate the sample area. Also included but not shown was the ability at room temperature to add exchange gas if the need arose. This capability was used to check the results found with apparatus \# 1 by dropping the temperature to $4.2 \mathrm{~K}$ occassionally during a $25 \mathrm{~K}$ run. A 4 inch piece of \#22 Cu wire was used to get a known thermal contact with the liquid helium bath. The sample holder is constructed exactly the same as holder \# 1 so no more need to be said about the construction of sample holder \#2. The high temperature capabilities of this apparatus are due to the fact that, besides the variable bleed wire used, the only path for cold conduction from the liquid helium is from the top plate via a short section of stainless steel tubing which is riddled with holes. These are needed to allow the sample chamber to be evacuated.

Presentation and Discussion of Experimental Results As stated above, our goal in this experiment was to find the magnetoresistance for each dilute $\mathrm{CuCr}$ alloy at $4.2 \mathrm{~K}$, and to measure the magnetoresistance of one sample as a function of temperature at a large applied external magnetic field.

The magnetoresistance of each CuCr alloy and a pure copper sample was measured at $4.2 \mathrm{~K}$ as outlined above using apparatus \# 1 . For ease 
THIS PAGE

WAS INTENTIONALLY

LEFT BLANK 
Figure 19. Sample holder $\$ 2$ used in CuCr magnetoresistance measurement from 4.2 to $35 \mathrm{~K}$. 


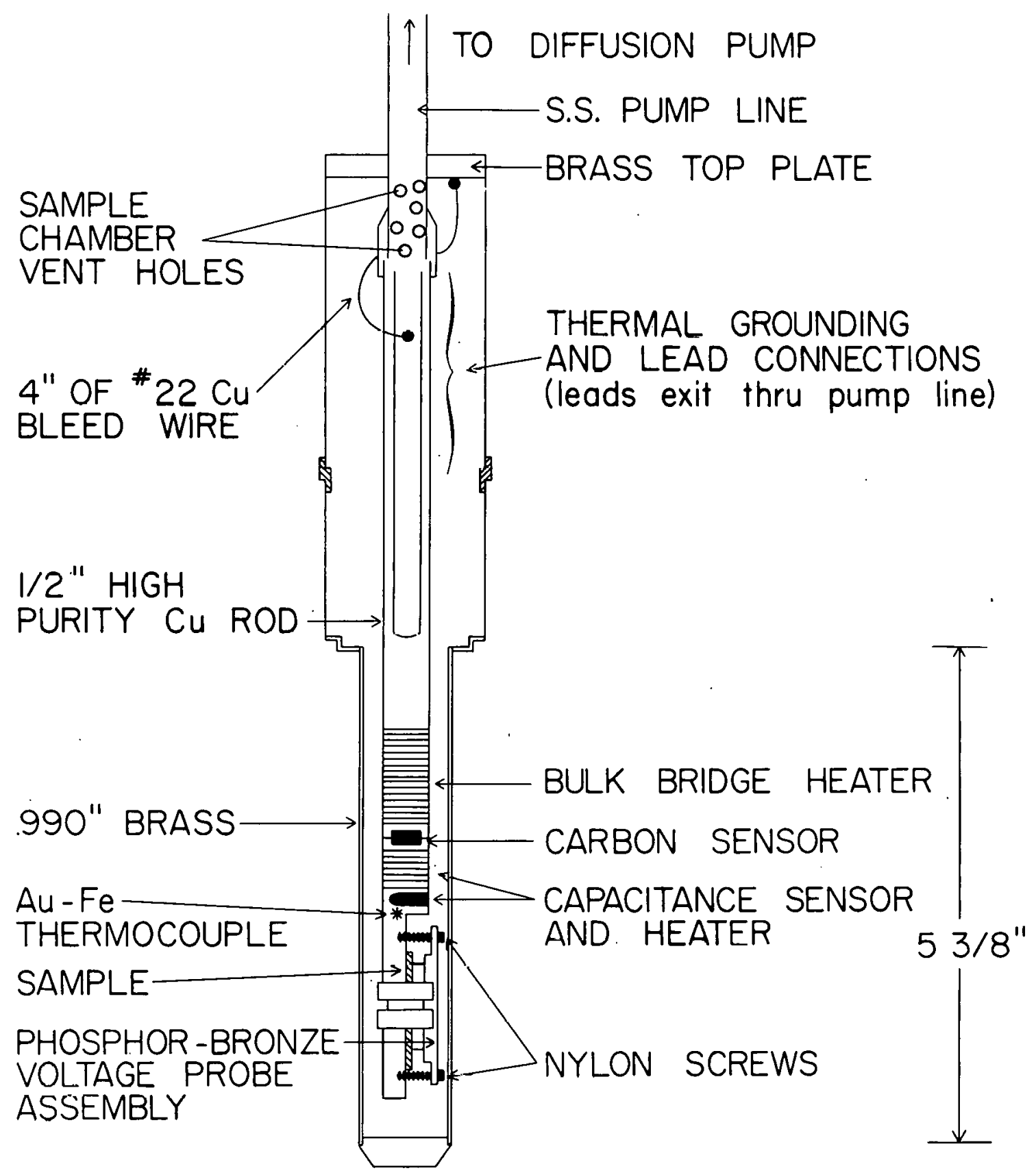


in plotting and comparing the various samples we have plotted the results of these measurements by subtracting the zero-field resistivity in each case. The result, $\rho(H)_{X C_{r}} \rho(H=0)$ is plotted versus applied magnetic field in Figure 20. As can be seen, the results seem nicely self-consistent in that the magnetoresistivity decreases for each alloy. The magnetoresistivity for pure Cu agrees very nicely with that found for pure $\mathrm{Cu}$ by Eagen (19) and Launay et al. (33). It had been suggested that the positive magnetoresistivity of the alloy could be suitably subtracted off merely by using the magnetoresistivity of pure $\mathrm{Cu}$. This procedure would be applicable only if the alloy matrix contribution to the magnetoresistivity was small. From the results of Eagen (19) on CuCr alloys with $\mathrm{Cr}$ concentrations up to $1,236 \mathrm{ppm} \mathrm{Cr}$, this seemed a likely method of subtraction. We therefore subtracted the magnetoresistivity of pure Cu from that of each alloy at 4.2K (See Figure 21). The results of Eagen's $114 \mathrm{ppm} \mathrm{Cr}$ alloy were included to show the extension of this procedure to higher concentrations. A rather surprising result was found. For the lower concentration alloys the implied spin magnetoresistivity was positive. This was due to basically the fact that no account had been taken of the positive magnetoresistivity due to the alloy matrix. As seen for these dilute alloys, the alloy matrix contribution is greater than the negative spin contribution at $4.2 \mathrm{~K}$. For the case of higher concentrations such as those studied by Eagen, the problem had never become apparent since the negative spin part at 4.2K easily dominated the positive alloy part. 
Figure 20. The total magnetoresistivity of pure $\mathrm{Cu}$ and each CuCr alloy ds a function of applied magnetic field at 4.2K. 


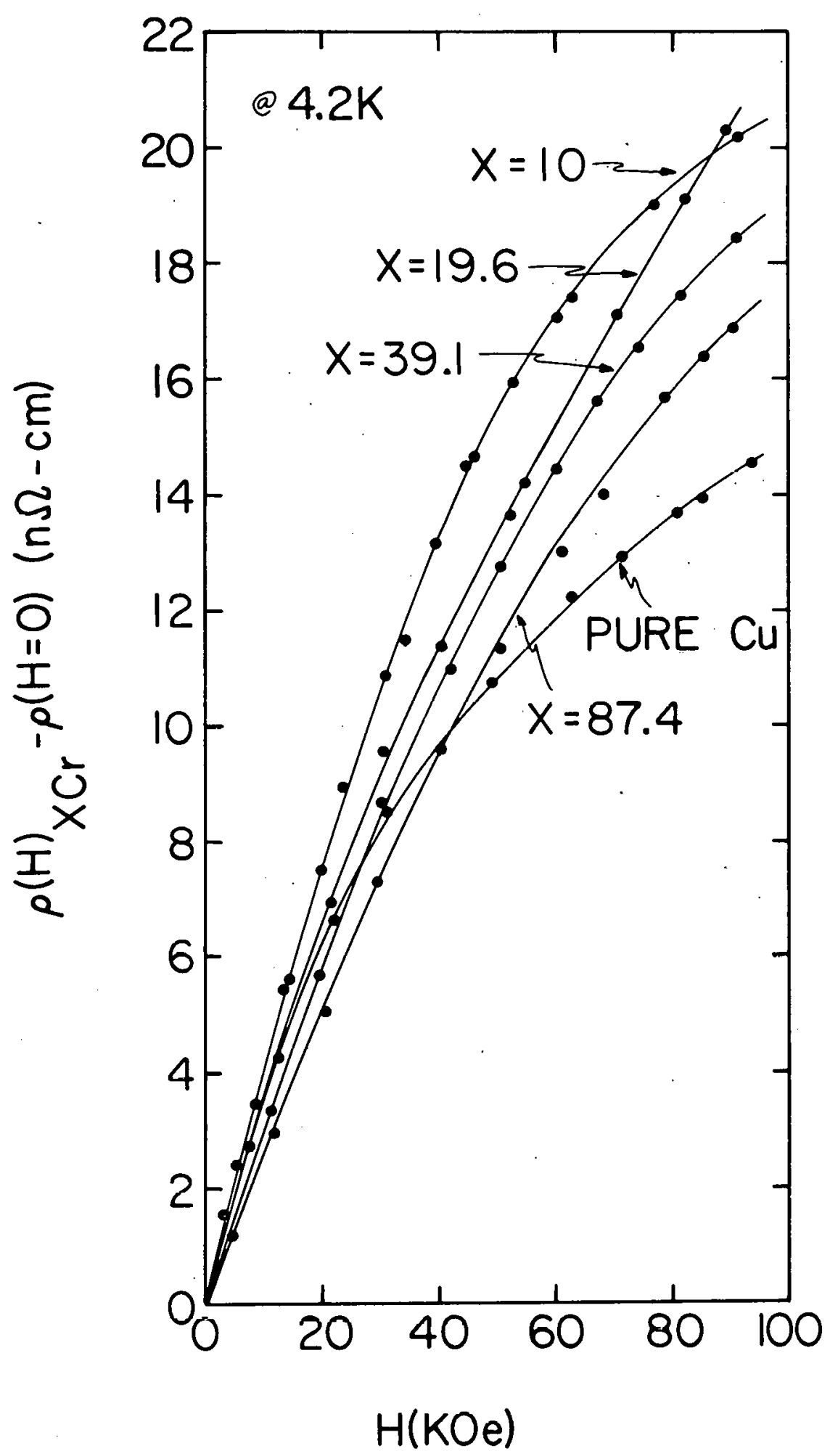


THIS PAGE

WAS INTENTIONALLY

LEFT BLANK 
Figure 21. The magnetoresistivity of each CuCr alloy minus that of pure $\mathrm{Cu}$ at $4.2 \mathrm{~K}$ as a function of applied magnetic field. 


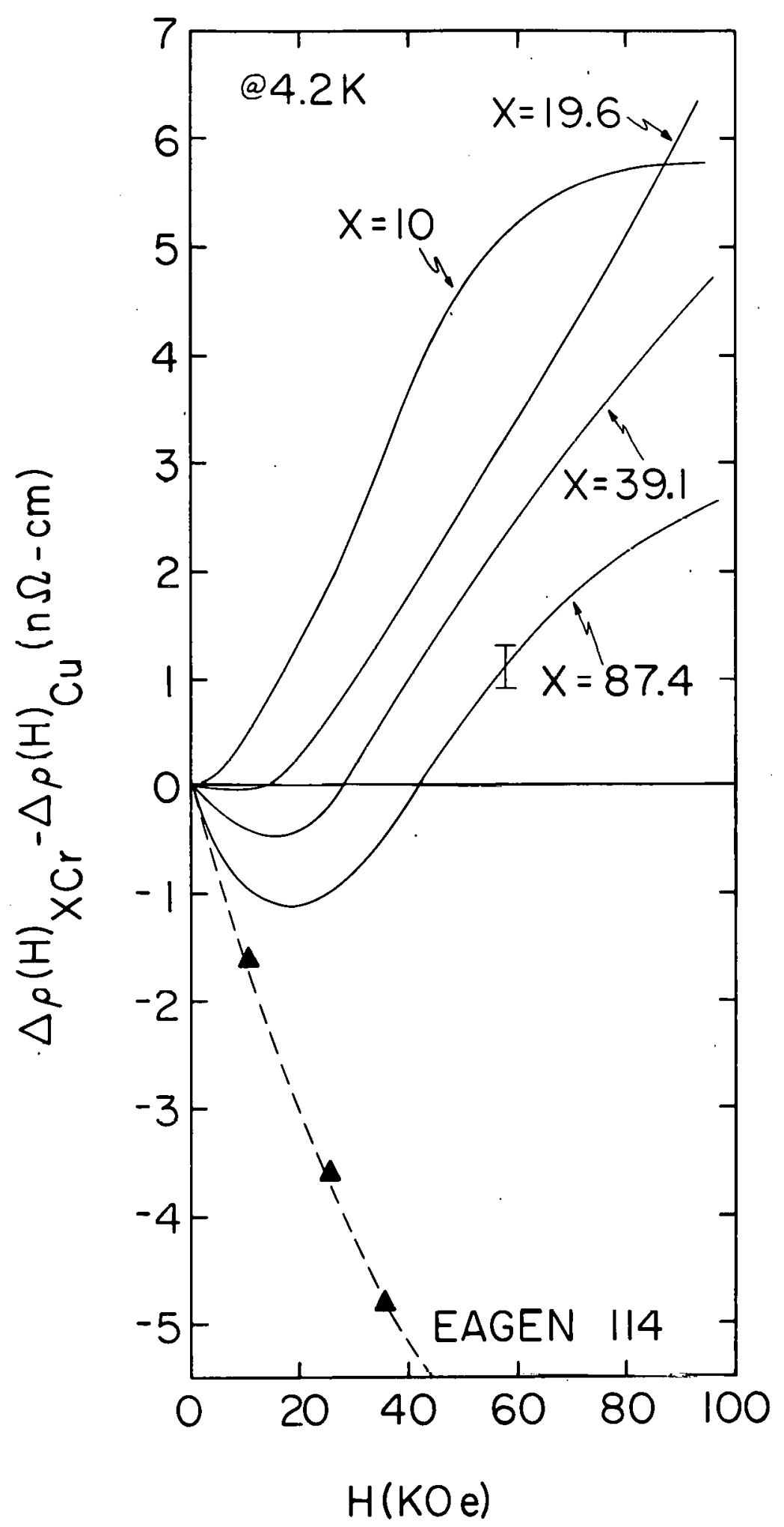


To find the real magnetoresistivity at $4.2 \mathrm{~K}$, we had to also subtract the positive alloy contribution. This was accomplished by measuring the magnetoresistivity as a function of applied field at $25 \mathrm{~K}$. This temperature was chosen since here the spin contribution and hopefully the phonon contribution to the magnetoresistivity would be negligible, leaving only the positive alloy matrix magnetoresistivity to be significant. The ideas and assumptions involved here can be found in the Theory section above.

To find the magnetoresistivity at $25 \mathrm{~K}$, apparatus \# 2 was employed as explained earlier. The results of the measurements have been plotted as $\rho(H) \mathrm{XCr}^{-} \rho(H=0)$ in Figure 22 as was done previously for the $4.2 \mathrm{~K}$ results. In this way only the field dependence is seen. As can be seen, up to $60 \mathrm{kOe}$ no difference was seen in the alloy magnetoresistivity for the four alloys at 25K. Above $60 \mathrm{kOe}$ the magnetoresistivity decreases roughly with concentration. The $19.6 \mathrm{ppm}$ sample shows slightly more effect but this is of little significance at these extremely high fields.

We took the magnetoresistivity at $4.2 \mathrm{~K}$ and subtracted from it that found at $25 \mathrm{~K}$. This procedure should give approximately the desired spin magnetoresistivity at $4.2 \mathrm{~K}$ for our particular alloys. The results of such a subtraction are shown in Figure 23. Here we see that the 87.4 and $39.1 \mathrm{ppm}$ samples show negative magnetoresistivity while the 19.6 and 10 ppm samples still have initial positive contributions. It is not entirely clear what is the reason for thi.s, but it 
THIS PAGE

\section{WAS INTENTIONALLY \\ LEFT BLANK}


Figure 22. The total magnetoresistivity of the CuCr alloys as a function of applied magnetic field at $25 \mathrm{~K}$. 


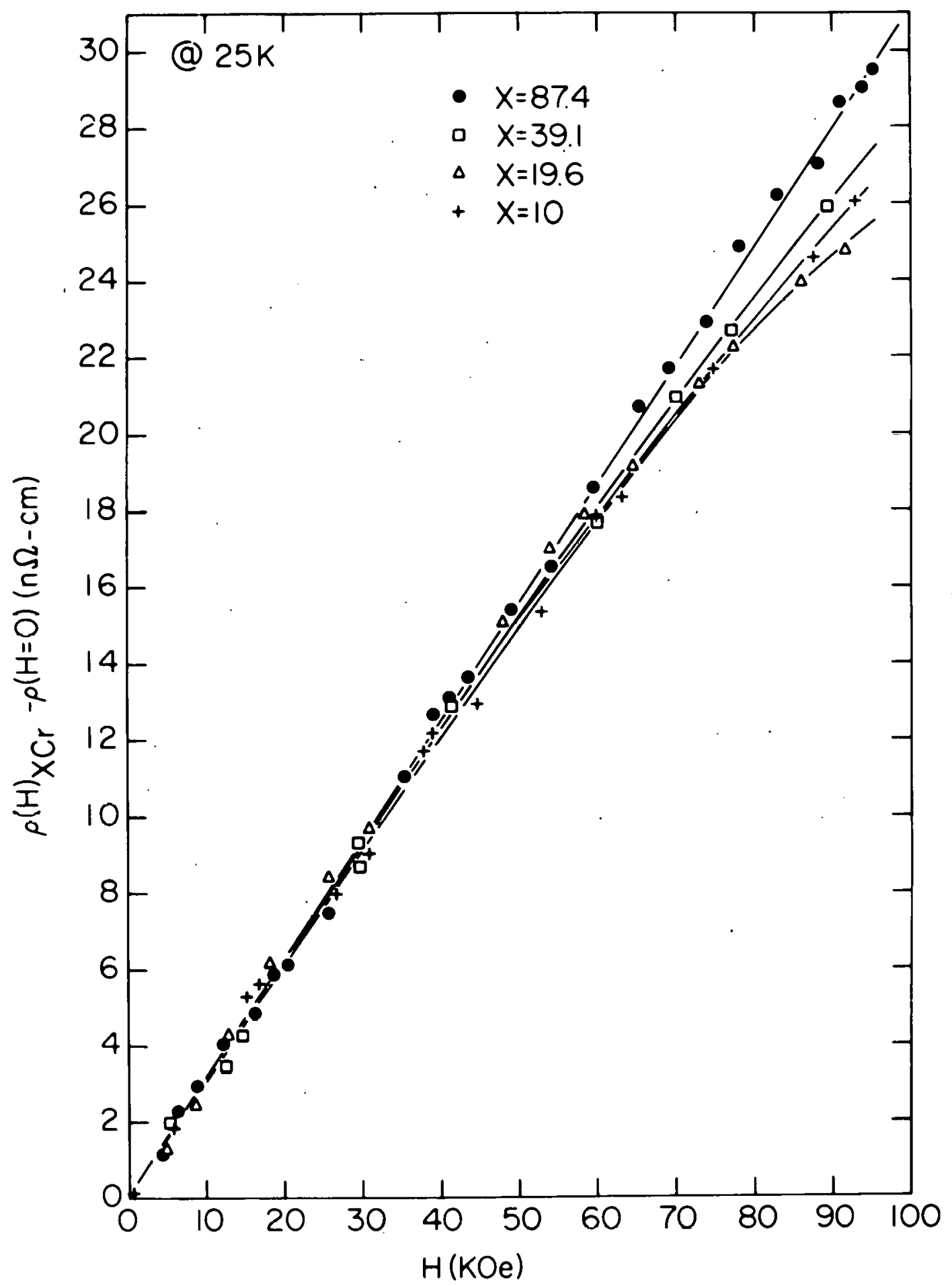


THIS PAGE

WAS INTENTIONALLY

LEFT BLANK 
Figure 23. The spin magnetoresistivity of the CuCr alloys as determined at $4.2 \mathrm{~K}$ by subtraction of the $25 \mathrm{~K}$ results. 


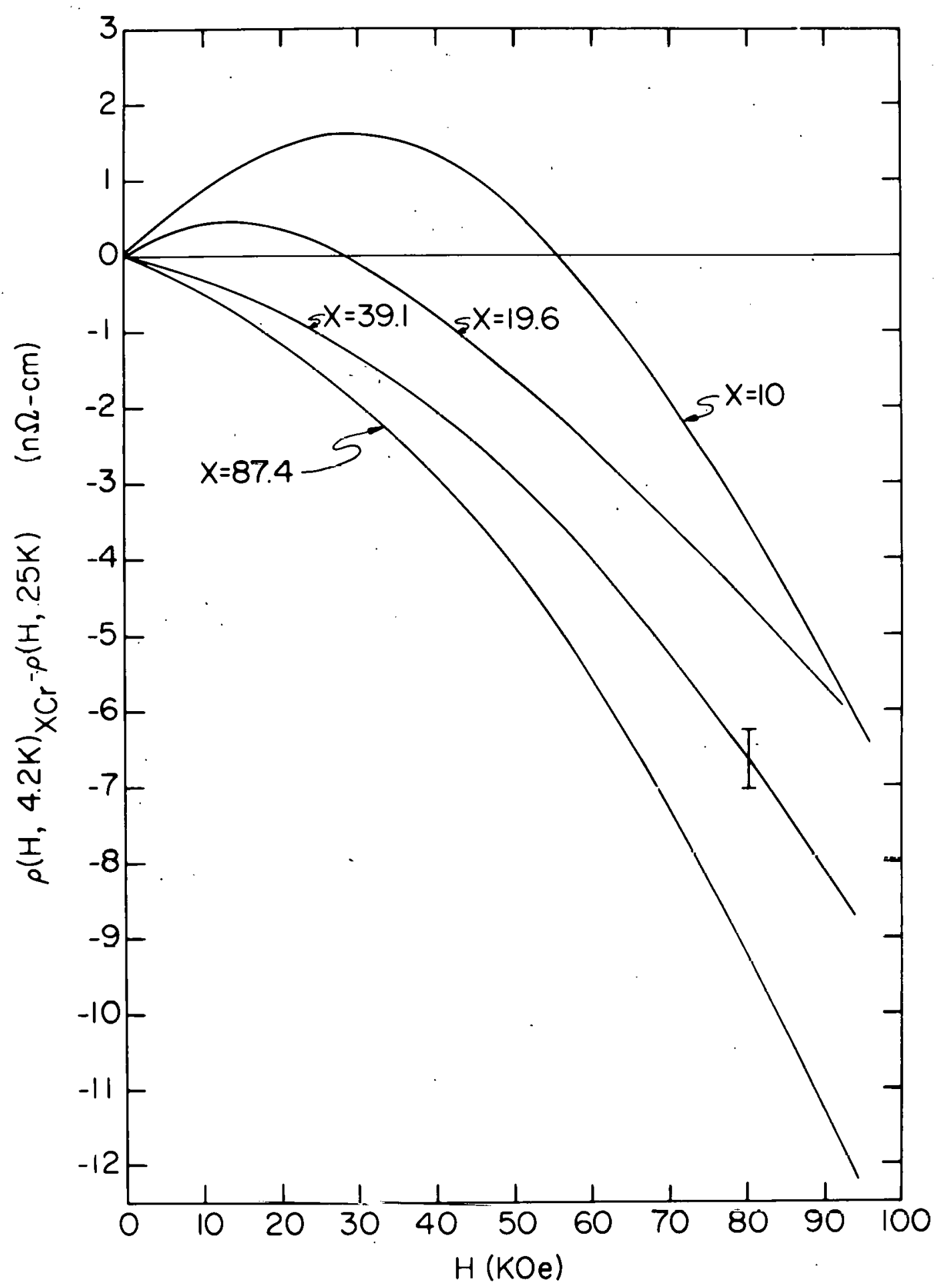


probably due to the fact that we have not done the positive subtraction correctly. It must also be remembered from the zero field residual resistivity results discussed in Chapter II that, for concentrations below about $60 \mathrm{ppm}$ at $25 \mathrm{~K}$ the residual resistivity is seen to level off. This would imply a break down in the strong, long range, $\mathrm{Cr}-\mathrm{Cr}$ interactions in this concentration region. At the considerably lower temperature of $4.2 \mathrm{~K}$, however, the break down of the $\mathrm{Cr}-\mathrm{Cr}$ interaction has probably not been entirely realized. This would make the results at $25 \mathrm{~K}$ for the positive contribution not really those at $4.2 \mathrm{~K}$ as assumed. The consequences of this, although, again probably small, add an additional uncertainty to the subtraction.

With all these uncertainties one can only look to slightly lower temperatures where the negative term should be significantly larger than at 4.2K. In this way some of the small positive term correction errors can hopefully be overshadowed by the increase in dominance of the negative spin term. To test this hypothesis we measured the magnetoresistivity of the $10 \mathrm{ppm}$ sample at $1.9 \mathrm{~K}$ in fields up to $90 \mathrm{~K} 0 \mathrm{e}$. The results are shown in Figure 24. Using this result the subtraction of the $25 \mathrm{~K}$ correction was again made (See Figure 25). Here we see that the spin magnetoresistivity is indeed negative. The functional form at high fields seems to be the same found at $4.2 \mathrm{~K}$. This is as it should be if we indeed are seeing subtraction errors in the $4.2 \mathrm{~K}$ result for the low concentration alloys.

As far as spin saturation is concerned, the following can be said. If spin saturation at high fields were to occur it would show 
THIS PAGE

\section{WAS INTENTIONALLY LEFT BLANK}


Figure 24. The total magnetoresistivity of the $10 \mathrm{ppm}$ sample at 1.9 and $4.2 \mathrm{~K}$. 


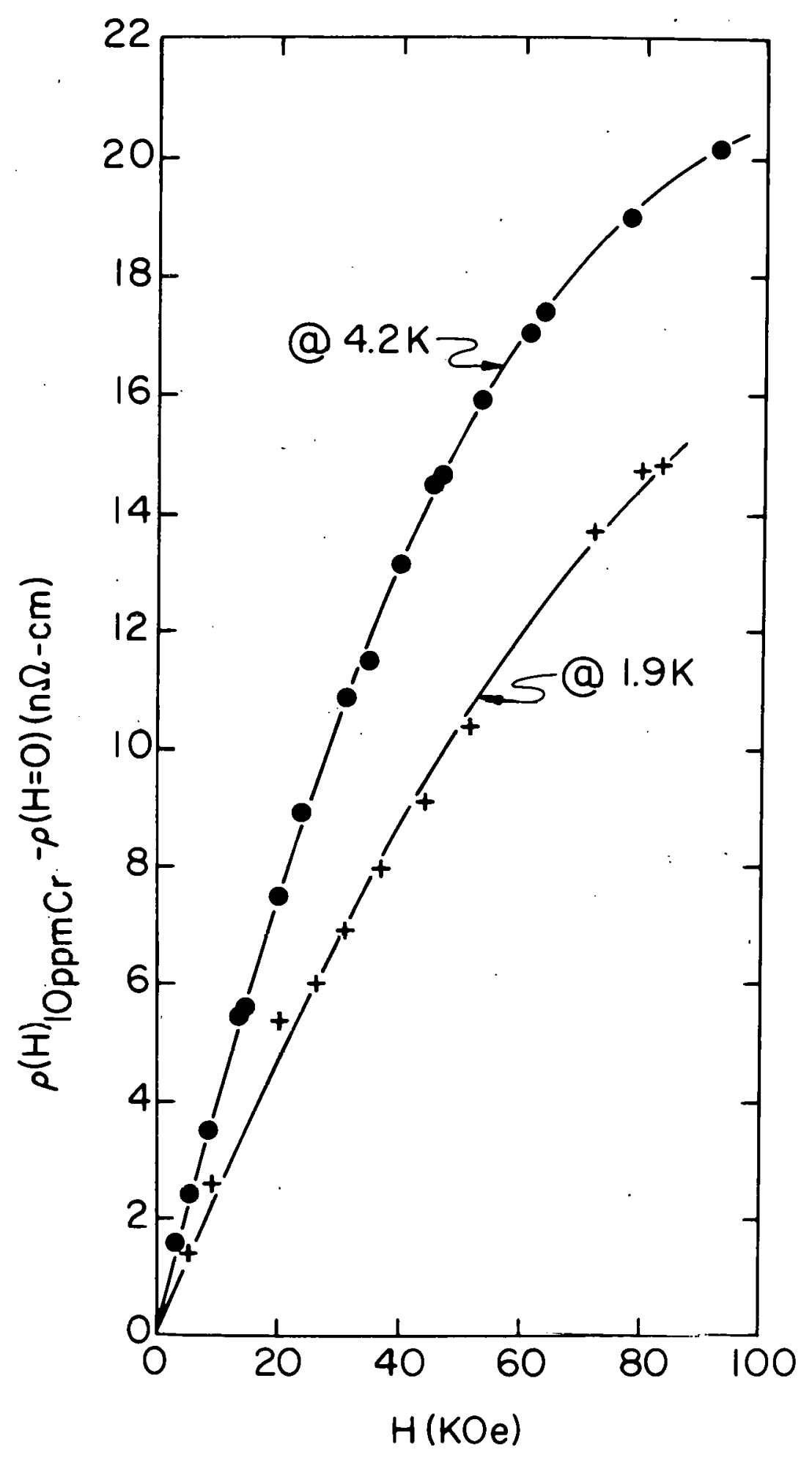


THIS PAGE

\section{WAS INTENTIONALLY LEFT BLANK}


Figure 25. The spin magnetoresistivity of the $10 \mathrm{ppm} \mathrm{Cr}$ sample at 1.9 and $4.2 \mathrm{~K}$ as determined by subtraction of the $25 \mathrm{~K}$ results. 


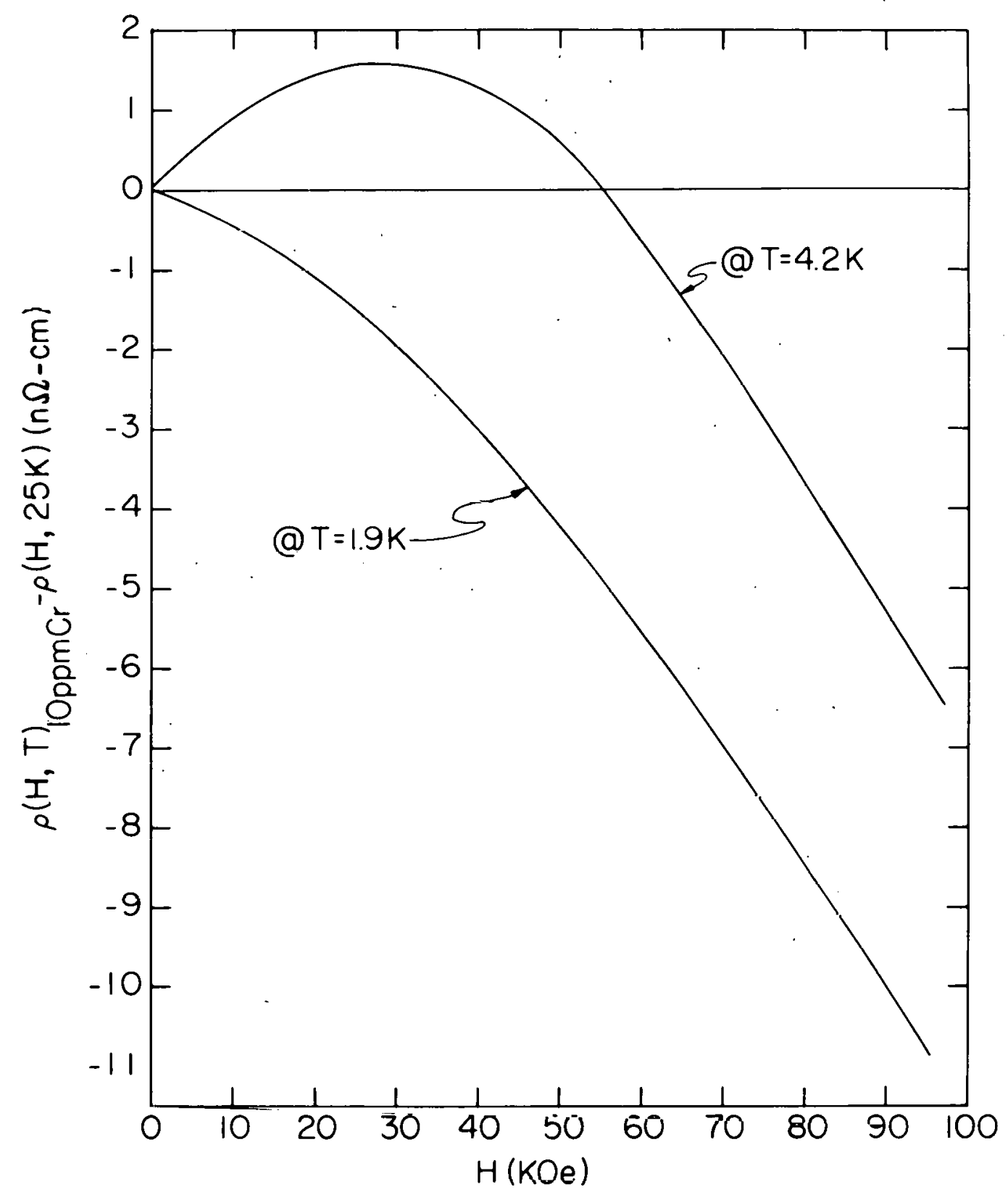


up on Figure 23. At low concentrations one would find a generally steeper negative slope than for the more concentrated alloys. This is seen not to be the case. When comparison is made to the $10 \mathrm{ppm}$ $1.9 \mathrm{~K}$ result it is even more clear that predicted spin saturation (26) was not observed.

To substantiate this, a measurement was made of the magnetoresistivity for the $10 \mathrm{ppm}$ sample as a function of temperature at a constant external magnetic field of $63 \mathrm{kOe}$. The results are shown in Figure 26 along with the zero-field result found in Chapter 11. The two plots have been constrained to agree asymptotically above $28 \mathrm{~K}$. As can be seen, at $63 \mathrm{kOe}$ the minimum is only slightly more shallow and spread out. Down to $4.2 \mathrm{~K}$, again no concrete evidence is seen to support the prediction for spin saturation.

\section{Conclusion}

The magnetoresistivity of $\mathrm{CuCr}$ alloys has been observed at $4.2 \mathrm{~K}$ in fields up to $95 \mathrm{k}$ ke. The spin magnetoresistivity of each alloy is found to be negative at $4.2 \mathrm{~K}$ as must be the case on general theoretical arguments. The exact procedure needed to obtain the spin magnetoresistivity quantitatively is seen to be highly complicated and unclear up to this point. The main problem centers around the determination of the positive magnetoresistivity at $4.2 \mathrm{~K}$. Our procedure has becn to assume that it is similar to that at $25 \mathrm{~K}$. This assumption is probably not quite valid as inferred from the slight positive spin term implied after subtraction for the $10 \mathrm{ppm}$ sample. In the 10 and 


\section{THIS PAGE}

WAS INTENTIONALLY

LEFT BLANK 
Figure 26. The majnetoresis:ivity versus temperature at 63 kije for the 10 ppm sample. 


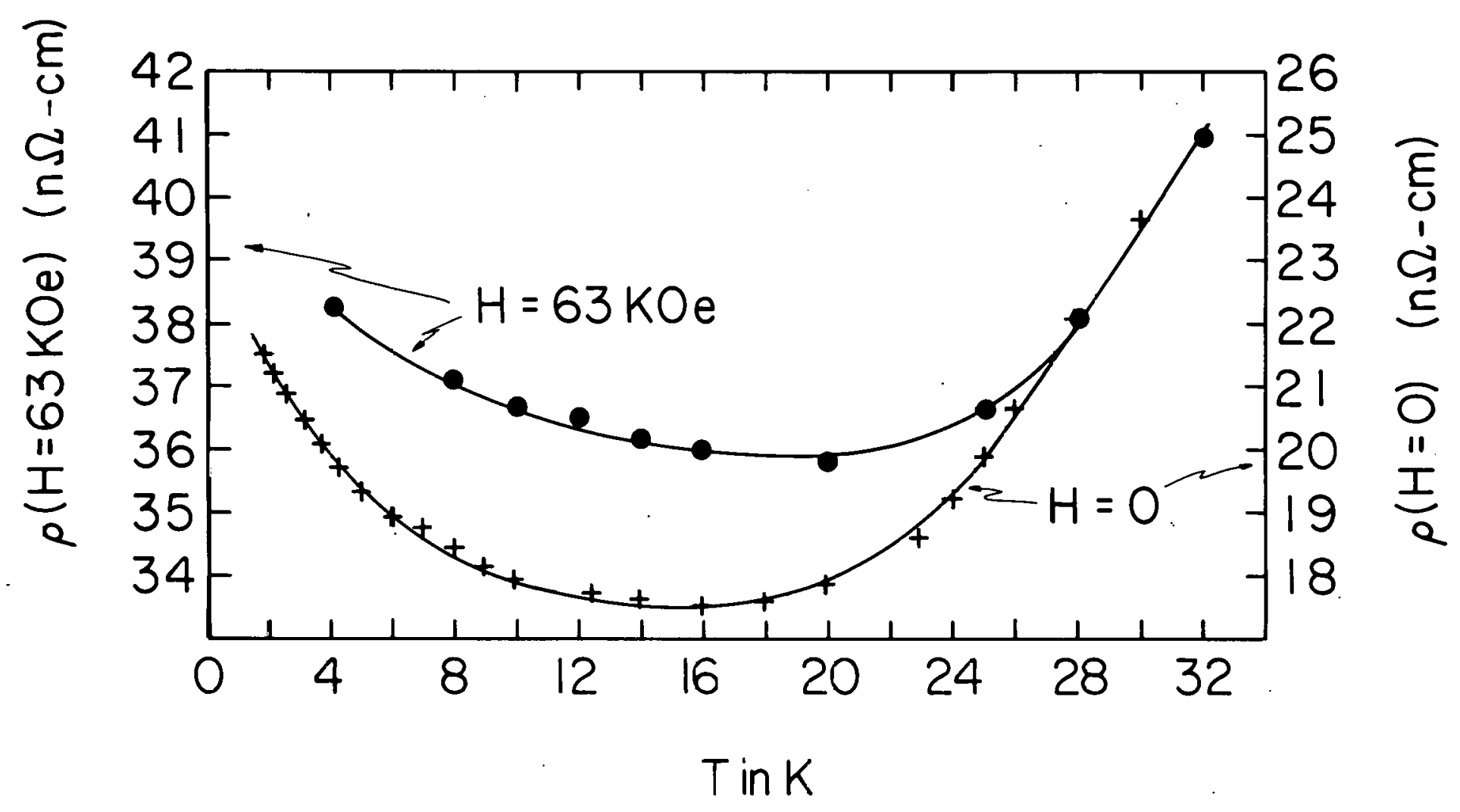


$19.6 \mathrm{ppm}$ sample, the $25 \mathrm{~K}$ correction is probably the most in error. This may be due to the implied break down of $\mathrm{Cr}-\mathrm{Cr}$ interactions for these alloys at $25 \mathrm{~K}$ which is probably not true at $4.2 \mathrm{~K}$. The small magnitude of the negative term is also a major problem for the 10 and 19.6 ppm sample. In general, the subtraction used is correct but there are significant places for error which need further study, both experimentally and theoretically.

The prediction has been made on theoretical grounds that the spin magnetoresistivity should saturate for these alloys at high fields and relatively low temperatures. No saturation was observed in the spin term of the magnetoresistivity for any of the alloys. This conclusion was further substantiated by a measurement of the magnetoresistivity of the $10 \mathrm{ppm}$ sample as a function of temperature at $63 \mathrm{kOe}$. The resistivity minimum was only slightly more shallow than that found at zero field with no evidence of saturation down to $4.2 \mathrm{~K}$. The problem here no doubt lies in the theoretical treatment of both internal and external field effects in that there seems to be no "freezing-out" of the spin-flip scattering. This is consistent with fallures in perturbative calculations for the high field susceptibility $(28,34)$. 


\section{REFERENCES}

1. W. Meissner and G. Voigt, Ann. Phys. I, 761 and 892 (1930).

2a. Wo J. dehaas, J. deBoer and G。 Jo van den Berg, Physica 1, 1115 $(1933 / 34)$; Commun. Leiden No. 233b.

b. W. J. detaas, H. B. G. Casimir and G. J. van den Berg, Physica $\underline{5}$, 225 (1938); Commun., Leiden No. 25lc.

c. Jo 0. Linde, Ann. Phys. 10, 52 and 69 (1931), 14, 353 and 15, 219 (1932).

d. J. Owen, M. E. Browne, W. D. Knight and C. Kittel, Phys。 Rev. 102, 1501 (1956).

e. A. N. Gerritsen and J. 0. Linde, Physica 18, 877 (1952); Commun., Leiden No. 290d.

f. G. K. White, Can. J. Phys. 33, 119 (1955).

g. W. B. Pearson, Phil. Mag. (7) 46, 920 (1955).

3a. M. D. Daybell and W. A. Steyert, Rev. Mod. Phys. 40, 380 (1968).

b. A. J. Heeger, Solid State Phys. 23 , 283 (1969)。

c. G. J. van den Berg, Phys. Status Solide (a) ㄱ, 11 (1970).

4. J. Kondo, Progr. Theoret. Phys。(Kyoto) 32, 37 (1964).

5. M. D. Daybell and W. A. Steyert, Phys. Rev。 Lett. 20, 195 (1968).

6. C. F. Eayen and S. Lcgvold, Phys. Rev. B6, 1830 (1972).

7. W. M. Star, Ph.D. thesis, Leiden (unpublished)。

8. C. Kittel, Introduction to Solid State (John Wiley \& Sons, Inc., New York, 1971).

9. W. D. Pcarson, Phil. Mag. 46, 920 (1955).

10. B. Knook, Ph.D. thesis, University of Leiden, 1962 (unpublished).

11. A. A. Abrikosov, Soviet. Phys. JETP 21, 660 (1965); (J. Expt1. Theoret. Phys. (U.S.S.R.) 48, 990 (1965). 
12. A. A. Abrikosov, Physics 2; 5,61 (1965)。

13. H. Suhl, Phys. Rev. 138 (1965) A515; Physics 2, 39 (1965).

14. H. Suhl and D. Wong, Physics 3, 17 (1967).

15. Y. Nagaoka, Phys. Rev。 138A, 1112 (1965)。

16. K. Fischer, Phys. Status Solidi (b) 46, 11 (1971)。

17. H. Gartner, D. R. Zradsky, and S. Legvold, Solid State Commun. $\underline{8}$, 913 (1970).

18. S. Legvold, D. T. Peterson, P. Burgardt, R. J. Hofer, B. Lundell, and T. A. Vyrostek, Phys. Rev. B, Mar. (1974).

19. Co. F。 Eagen, Ph.D. thesis, lowa State University (1972) (unpublished).

20. M. S. Anderson, H. T. King and C. A. Swenson, Ames, lowa. Calibration of Au Fe vs. Cu thermocouples. Private communication.

21. L. L. Sparks, R. L. Powell and W. J. Hall, Cryogenic Thermocouple Tables. National Bureau of Standards Report No. 9712, 1968.

22. D. W. Mellon, Ph.D. thesis, lowa State University (1970) (unpublished).

23. B. B. Triplett and N. E. Phillips, Proc, 12th Intl。 Confo on Low Temp. Physics, edited by E. Konda (Kyoto, 1971), p. 747.

24. A. Jo Croft, E. A. Faulkner, Jo Hatton and E. Fo. Seymour, Phil: Mag. 44, 289 (1953).

25. P. Munod, Phys. Rev. Lett. 19, 1113 (1967).

26. M.-T。, Béal-Monod and Weiner, R. A., Phys. Rev。 170, 552 (1968).

27. R. Moore and H. Suhl, Phys. Rev。 Lett. 20, 500. (1968)。

28. P. E. Bloomfield, R. Hecht and P. R. Sievert, Phys. Rev. B2, 3714 (1970).

29. A. R. Harvey, Ph.D. thesis, lowa State University (1971) (unpublished). 
30. Y. K. Yeo, Ph.D. thesis, University of Southern California at Los Angeles (1972) (unpublished).

31. J. E. A. Alderson and.C. M. Hurd, Jo Phys. Chem. Solids 32, 2075 (1971).

32. D. B. Richards, Ph.D. thesis, lowa State University (1968) (unpubli shed)。

33. Jo de Launay, R. L. Dolecek and R. T. Webber, Jo Phys. Chem。 Solids II, 37 (1959).

34. G. Biovannini, R. Paulson, and J. R. Schrieffer, Phys. Lett. 23, $517(1966)$. 


\section{ACKNOWLEDGMENTS}

In this section 1 am given the opportunity to recognize the people, present and past, who have been a major influence on my graduate career. There are many, of course, but a few stand out in my mind.

I would like to express my appreciation to my wife Kathleen. Graduate life is the hardest on wives, especially those of the experimentalist. All through the many evenings and nights alone, her optimism and confidence in my abilities were the major driving force in doing just a few more data points. Even after a year of non-existent weekends, her patience grew only slightly thin.

Scholastically, one must mention Dr. Sam Legvold. Serving as my major professor, Sam was the key to my many experimental successes. He always had confidence in my abilities even when sample chambers leaked or electronics failed. One must also remember the many "spirited" dinners that he and his wife Lavona gave throughout our stay in Ames.

1. would also like to thank my colleague Paul Burgardt for helping wi th many Friday night and weekend "projects". Our personality similarities and differences led to many very interesting experiences.

Much appreciation goes to $A$. Johnson for the sample preparation. 
I would like to list a few names which have made lasting impressions on me. They are: Dr. Dave Johnson, Dr. Joe Schaefer, Dr. Bob Green, Duane Dolesji, and Mike Glascock. These people have contributed in various ways too numerable to mention to my graduate study. Finally, much thanks goes to my typist Pat Borts. 
APPENDIX A.

\section{- LIST OF EQUIPMENT USED IN DETERMINATION \\ OF RESISTIVITY OF CUCr ALLOYS}

The basic equipment used in the electronic circuits is listed in Table A-1. The numbers in parentheses are Ames Laboratory equipment numbers.

Table A-1. List of equipment for resistivity of CuCr alloys

\begin{tabular}{ll}
\hline \multicolumn{1}{c}{ Description } & \multicolumn{1}{c}{ Company } \\
\hline $\begin{array}{l}\text { Potentiometer for sample emf } \\
\text { Nanovolt amplifier }\end{array}$ & Honeywell 2768 (11376) \\
$\begin{array}{l}\text { Secondary galvanometer } \\
\text { Potentiometer for sample current } \\
\text { and temperature }\end{array}$ & Guildline 9460A (17648) \\
$\begin{array}{l}\text { Null detectors } \\
\begin{array}{l}\text { Decade resistor for temperature } \\
\text { control bridge }\end{array}\end{array}$ \\
$\begin{array}{l}\text { Power supply for temperature } \\
\text { control bridge }\end{array}$ \\
$\begin{array}{l}\text { Proportional temperature } \\
\text { controller }\end{array}$
\end{tabular}


APPENDIX B.

TABULATION OF CUCr RESISTIVITY DATA

In Table $\mathrm{B}-1$ the resistivity, $\rho$, is given in $\mu \Omega \mathrm{cm}$, the impurity contribution to the resistivity, $\Delta \rho$, is given in $\mu \Omega \mathrm{cm}$ and the temperature, $T$, is given in $K$.

Table B-1. CuCr. resistivity data

\begin{tabular}{llllll}
\hline & $\rho$ & $\Delta \rho$ & $T$ & $\rho$ & $\Delta \rho$ \\
\hline
\end{tabular}

Cu (run 2)

$\begin{array}{lllll}1.90 & 0.0073 & \ldots & 30.12 & 0.0129 \\ 2.10 & 0.0072 & 39.84 & 0.0269 & \ldots \\ 2.50 & 0.0072 & 44.27 & 0.0363 & \ldots \\ 3.20 & 0.0072 & 46.06 & 0.0417 \\ 3.49 & 0.0072 & 48.10 & 0.0485 \\ 3.86 & 0.0072 & 53.70 & 0.0709 \\ 4.10 & 0.0072 & 56.54 & 0.0814 \\ 4.17 & 0.0071 & 66.10 & 0.1250 \\ 4.66 & 0.0071 & 70.15 & 0.1495 \\ 5.06 & 0.0071 & 76.10 & 0.1883 \\ 5.86 & 0.0071 & 77.76 & 0.2070 \\ 6.06 & 0.0071 & & \\ 7.52 & 0.0071 & & \\ 9.05 & 0.0070 & & \\ 10.07 & 0.0070 & 1.66 & 0.0080 \\ 12.07 & 0.0070 & 1.89 & 0.0084 \\ 13.03 & 0.0070 & 2.51 & 0.0084 \\ 14.07 & 0.0071 & 3.06 & 0.0082 \\ 15.08 & 0.0072 & 3.83 & 0.0081 \\ 16.12 & 0.0072 & 4.40 & 0.0082 \\ 17.16 & 0.0073 & 4.72 & 0.0081 \\ 18.01 & 0.0074 & 4.83 & 0.0079 \\ 19.05 & 0.0075 & 4.94 & 0.0075 \\ 20.08 & 0.0076 & 5.06 & 0.0075 \\ 21.98 & 0.0081 & 5.10 & 0.0072 \\ 23.06 & 0.0085 & 5.26 & 0.0071 \\ 24.25 & 0.0090 & 5.86 & 0.0072 \\ 25.10 & 0.0096 & 6.65 & 0.0073 \\ 26.01 & 0.0100 & 7.64 & 0.0072 \\ 28.03 & 0.0113 & & \end{array}$


Table 8-1. Continued

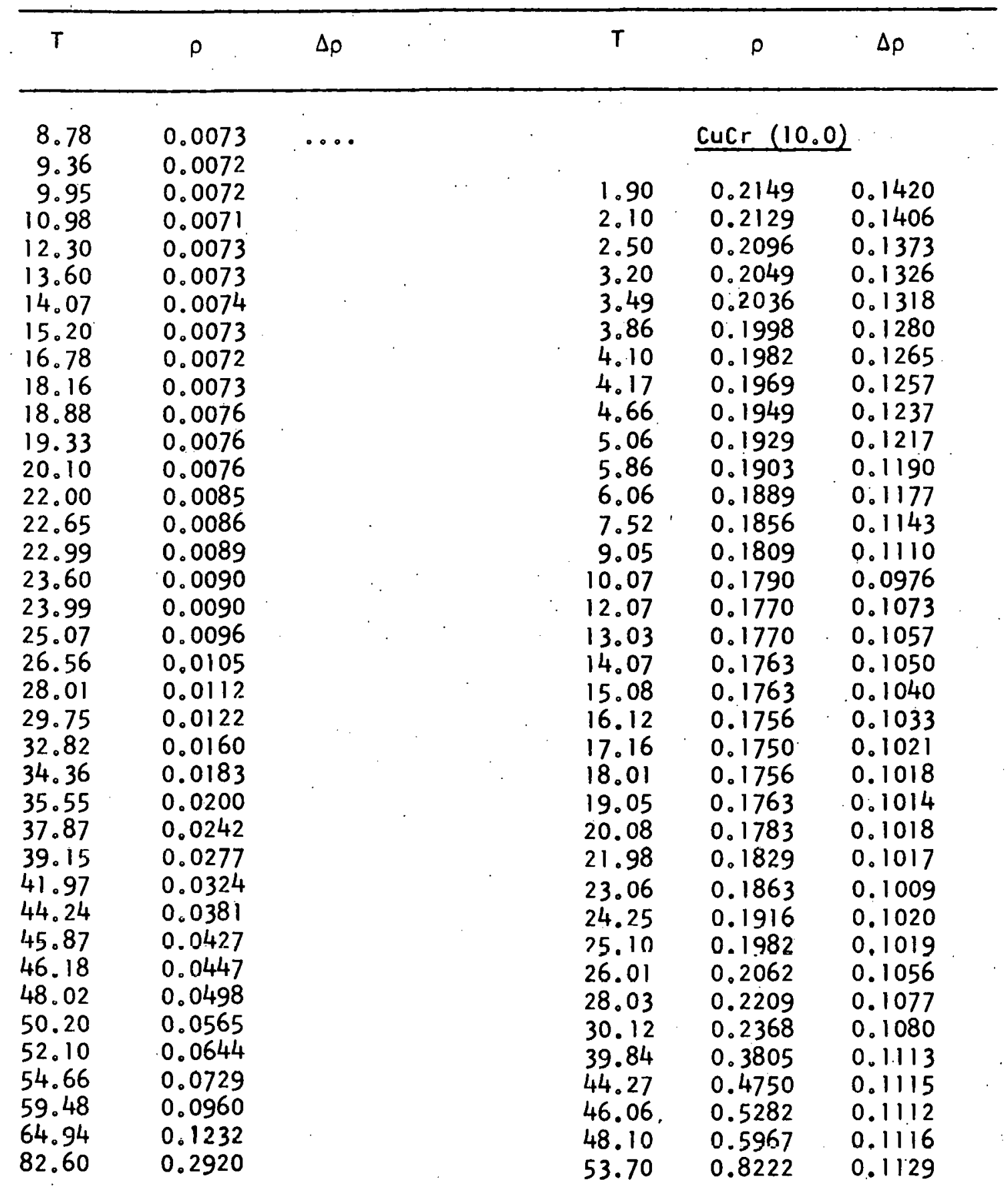


Table B-1. Continued

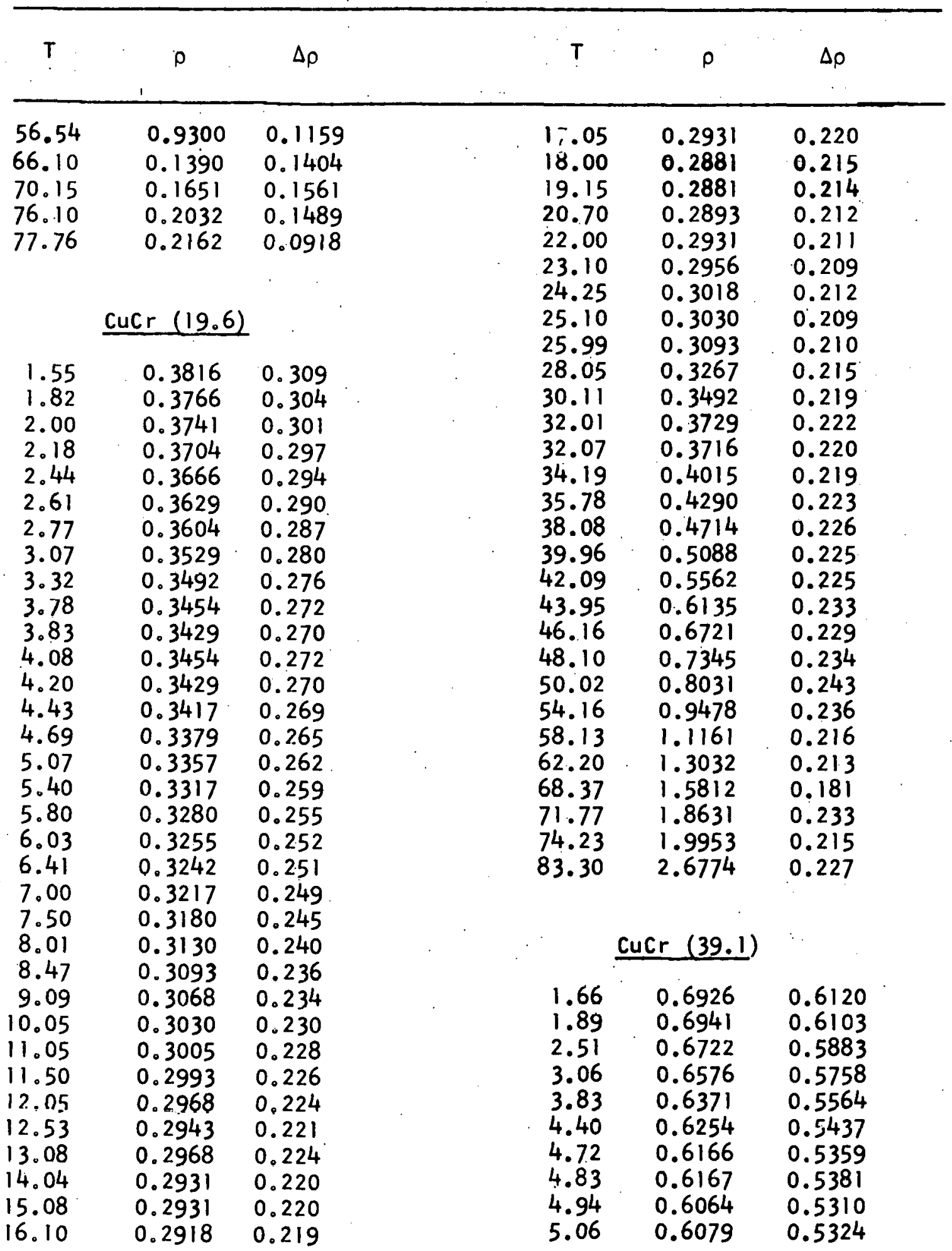


Table B-1. Continued

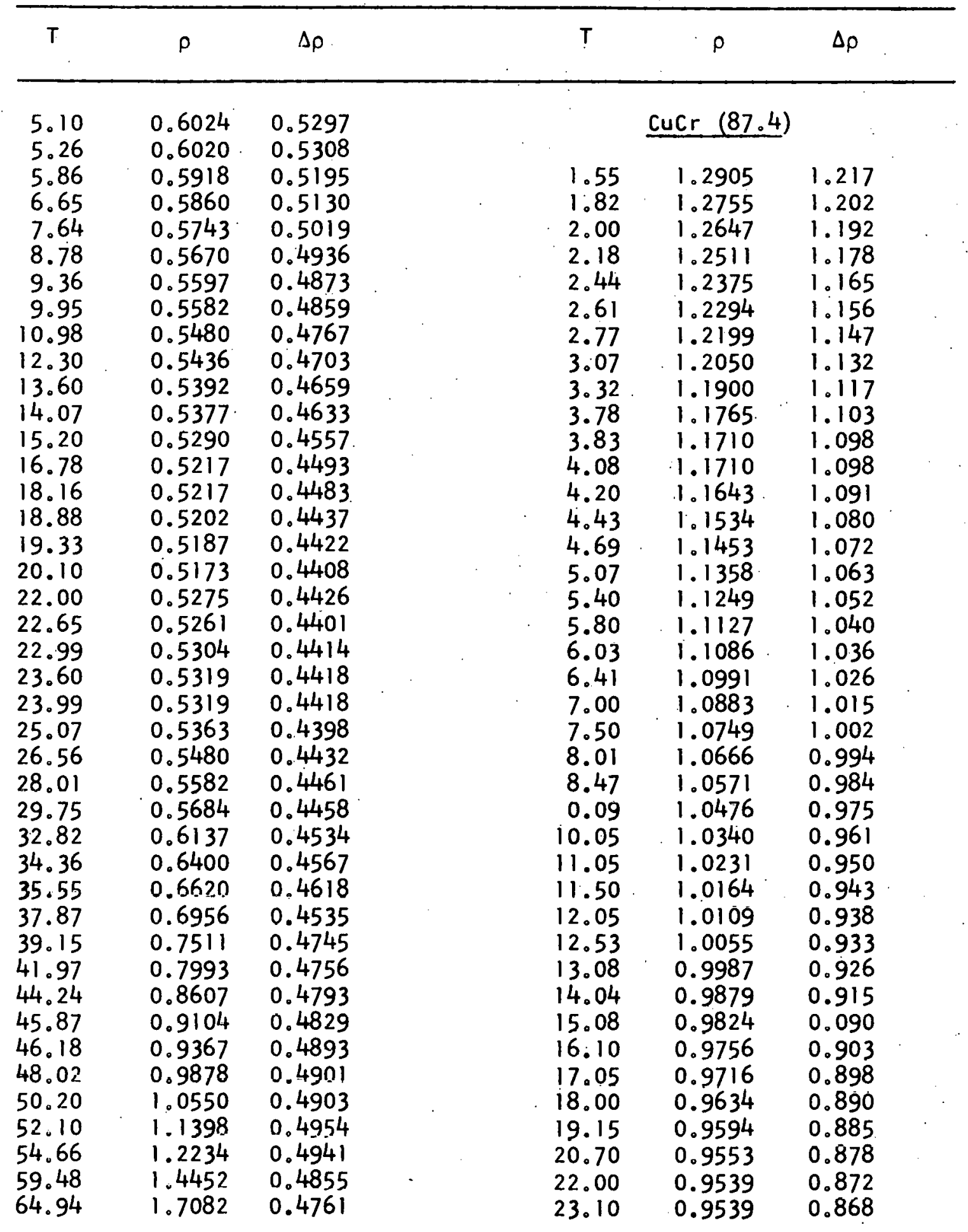


Table B-1. Continued

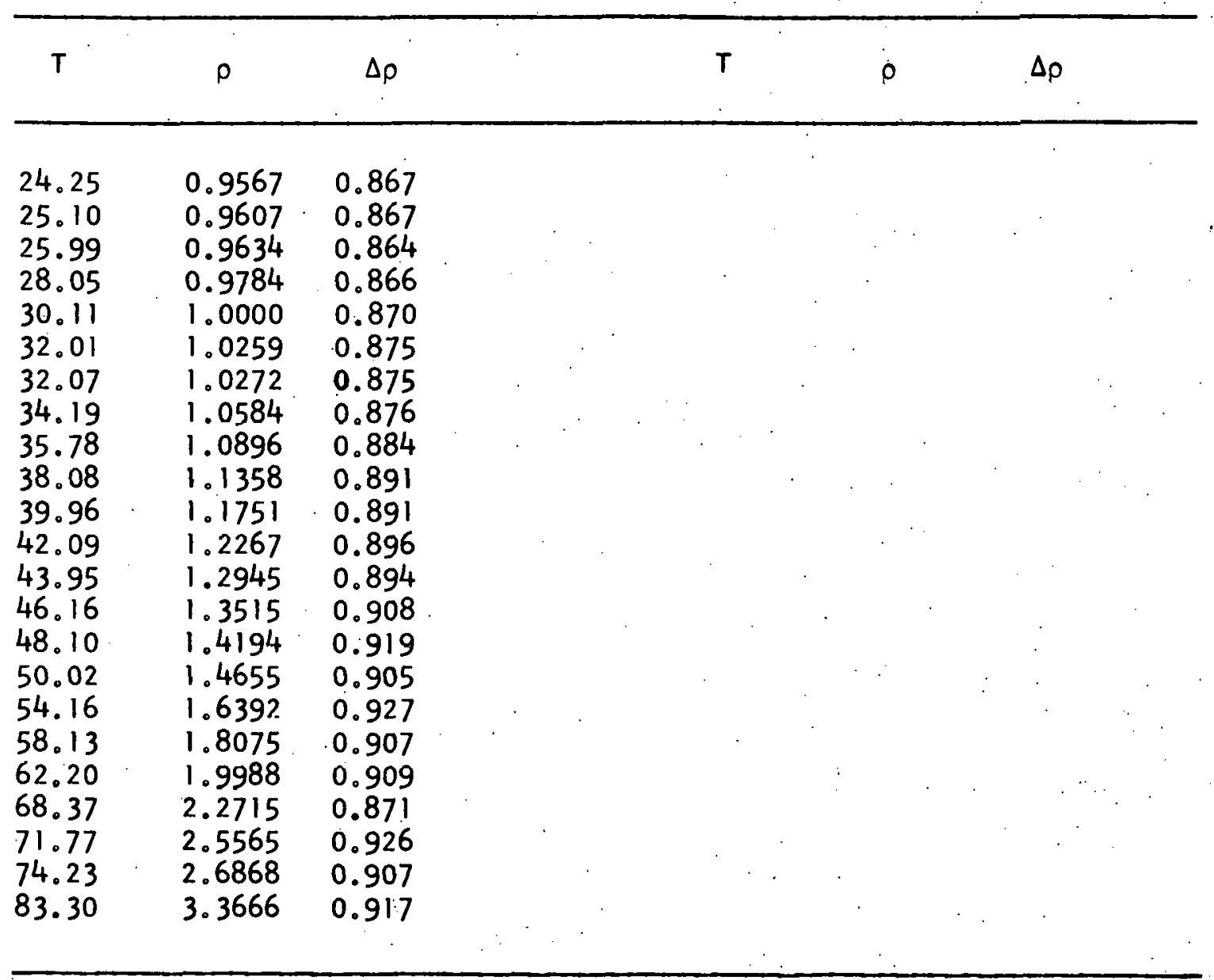


APPENDIX C .

\section{LIST OF EQUIPMENT USED IN DETERMINATION \\ OF THE MAGNETORESISTIVITY OF CUCr ALLOYS}

The basic equipment used in the electronic circuits is listed

in Table $\mathrm{C}-1$. The numbers in parentheses are Ames Laboratory

equipment numbers.

Table C-1. List of equipment for magnetoresistivity of $\mathrm{CuCr}$ alloys

Description

Company

\begin{tabular}{|c|c|}
\hline Potentiometer for sample and AuFe emf & $\begin{array}{l}\text { L. E N. } 7555 \text { Type K-5 } \\
(14229)\end{array}$ \\
\hline $\mathrm{K}-5$ gal vanometer & L. \& N. 9834 (13738) \\
\hline Potentiometer for field determination & $\begin{array}{l}\text { L. E N. } 7553-6 \text { Type K-3 } \\
(13737)\end{array}$ \\
\hline $\mathrm{K}-3$ galvanometer & L. \& N. 9834 (14177) \\
\hline K-3 current supply. & $(11596)$ \\
\hline $\begin{array}{l}\text { Decade resistor for temperature } \\
\text { control bridge }\end{array}$ & L. E N. $4756(8420)$ \\
\hline $\begin{array}{l}\text { Power supply for temperature } \\
\text { control bridge }\end{array}$ & $\begin{array}{l}\text { Kepco CK18 - } 3 M \\
(14350)\end{array}$ \\
\hline Proportional temperature controller & $(16576)$ \\
\hline Capacitance bridge & $\begin{array}{l}\text { Lake Shore Cry. Model CSC } \\
400(18335)\end{array}$ \\
\hline $\begin{array}{l}\text { Superconducting solenoid current } \\
\text { supply }\end{array}$ & Harvey-Wells CFC - 100 \\
\hline
\end{tabular}

